\title{
القيم الدينية والجمالية في (ابتهال الله اسم الذات) للهلباوي *
}

إعداد - اد

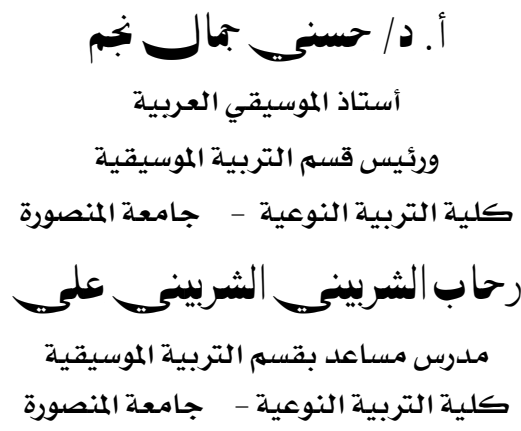

أ. دمالح/ صالح رضا صالح

أستاذ الموسيقي العربية

كلية التربية الموسيقية الموبية

جامعة حلوان

د/ أحمد فريد محمودة

مدرس الإدارة والتخطيط التربوي

كلية التربية النوعية - جامعة المنصورة

مجلة بحوث التربية النوعية ـ جامعة المنصورة

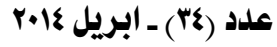

بحث مستل من رسالة دكتوراه 


\section{القيم الدينية والجمالية في (ابتهال الاله اسم الذات) للهابباوي}

إعداد

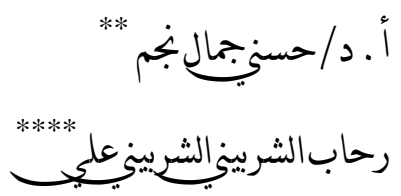

$$
\text { أ. د دالحمرضا صالح فريد محمود }
$$

\section{:}

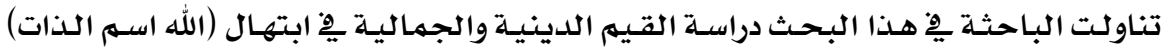

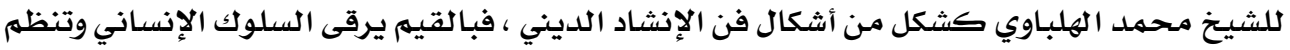

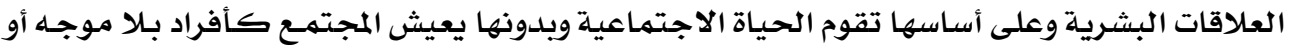

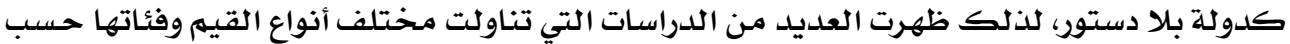

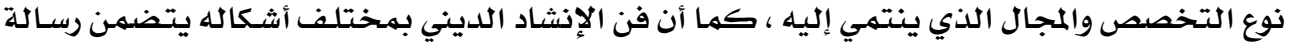

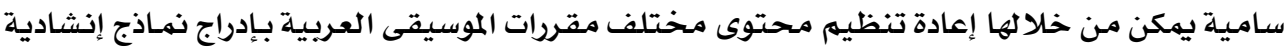

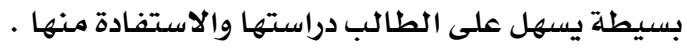
الإطار النظري : (1) وتناولت فيه الباحثة العناصر التالية :

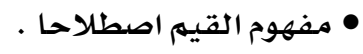

• تصنيف القيم : حيث ان لها تصنيفات عديدة مختلفة لأنها تدخل ِِّف كثير من مجالات الحياة،

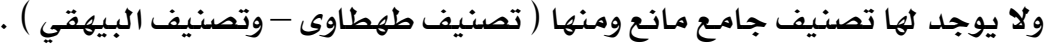

$$
\begin{aligned}
& \text { • مفهوم الابتهال الديني وأسلوب أدائه }
\end{aligned}
$$

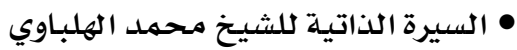

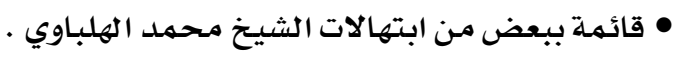

الإطار التطبيقي :

$$
\begin{aligned}
& \text { وتناولت فيه الباحثة العناصر التالية : } \\
& \text { • تدوين ابتهال ( الله اسهم الذات ) للهلباوي • }
\end{aligned}
$$

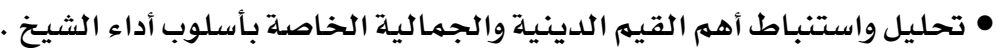


يزخر فن الابتهال الديني بالعديد من فئات القيم الدينية حيث استطاعت الباحثة استنباط

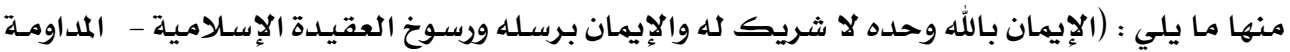

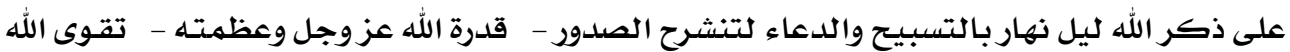

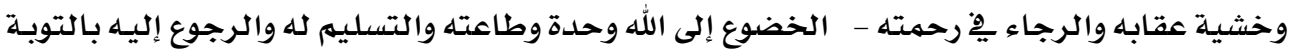

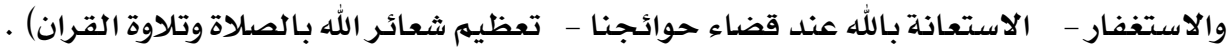
تمكن الشيخ محمد الهلباوي من أداء العديد مـن القيم الجماليـة الخاصـة بأسـلوب الأداء

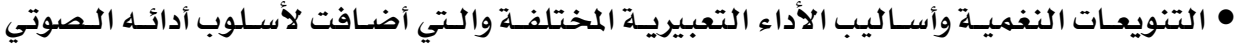

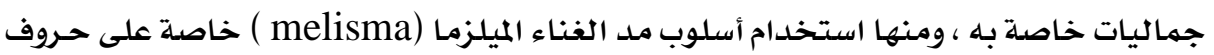

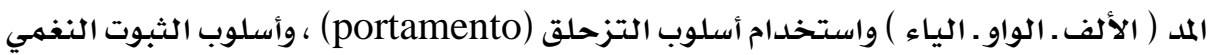

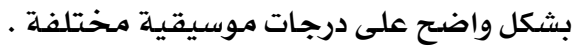

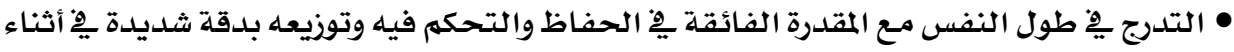
أداء المقاطع · •

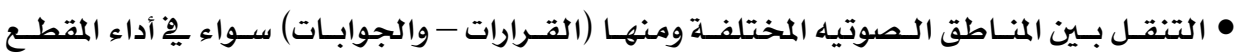

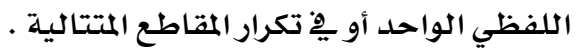

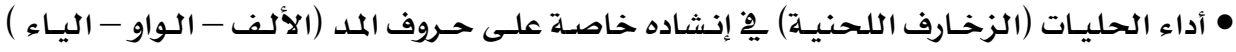

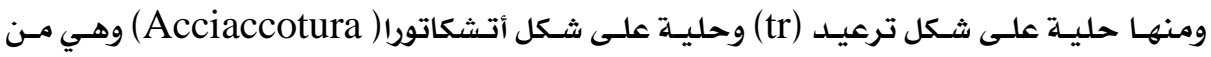
الحليات الشائع استعملها يْ موسيقانا العربية الأصيلة.

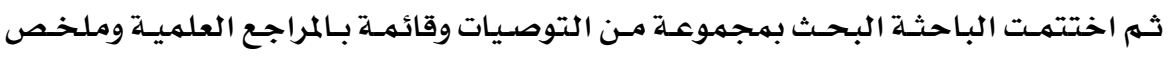

بالقيم يرقى السلوك الإنساني ويصل إلى أحسن حال يِّ الدنيا وأكمل الدرجات يِّا الآخرة ،

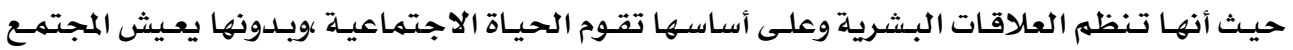

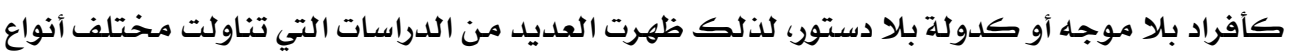

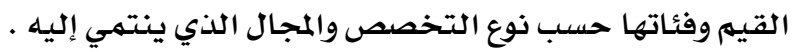
وانطلاقا من تلك الأهمية للقيهم وقوة ارتباطها بالتربية يِّ المراحل التعليمية المختلفة فقدس

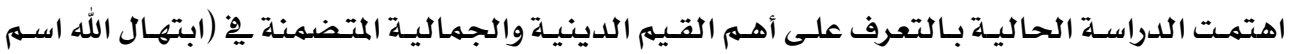

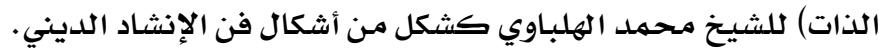




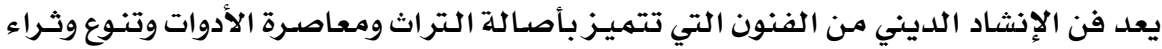

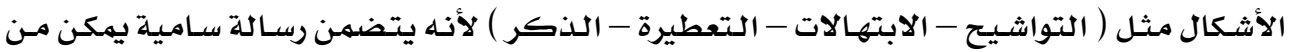

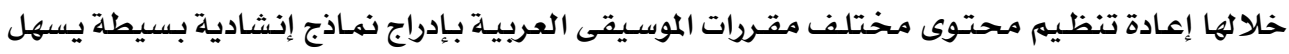

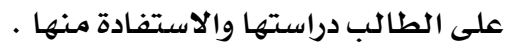

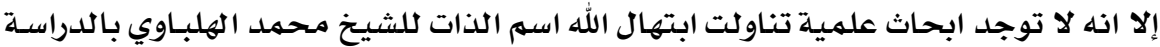

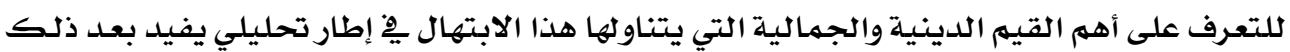

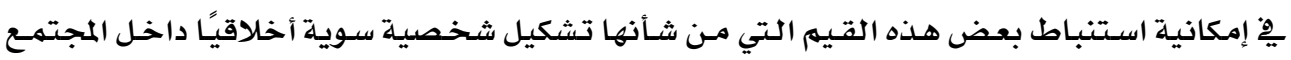

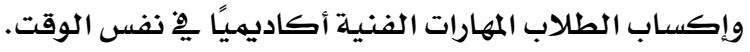
ويتحدد موضوع البحث الحالي يْ السؤال الرئيس التالي :

• ما القيم الدينية والجمالية يِّا ابتهال الله اسم الذات للشيخ محمد الهلباوي؟ ويتفرع عن هذا السؤال الرئيس الأسئلة الفرعية التالية :

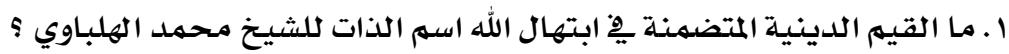

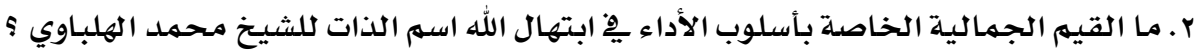

ا ـ التعرف على القيم الدينية يِّ ابتهال الله اسم الذات للشيخ محمد الهلباوي.

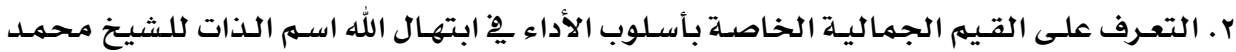

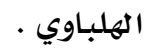

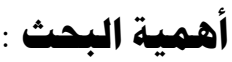

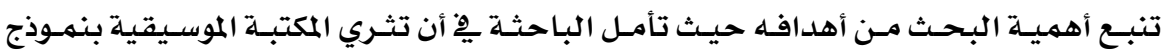

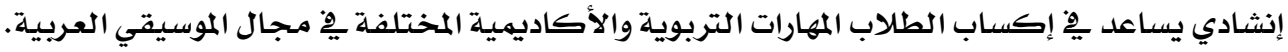

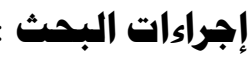 أولا : منهج البحثٌ :}

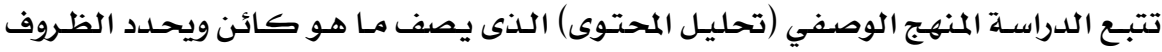

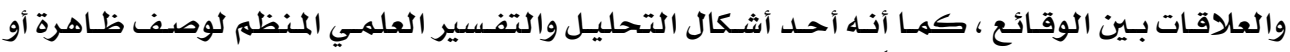

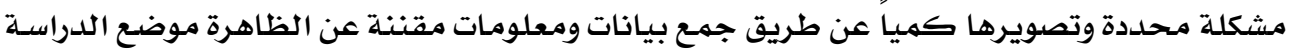

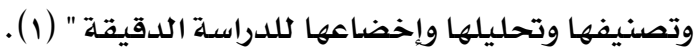

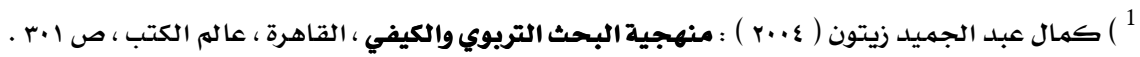




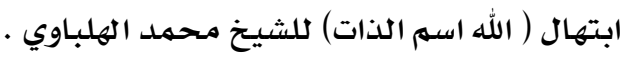

ثانيا : أدوات البحث : (1)

• • التسجيل الصوتي للابتهال .

• • المدونة الموسيقية للابتهال .

هصطات الدراسة :

• القيه:

تعرف لغويا بأنها :" قوم الشيء : قدر قيمته ـ وقوام كل شيء : عماده ونظامـه. وقيمة الشيء

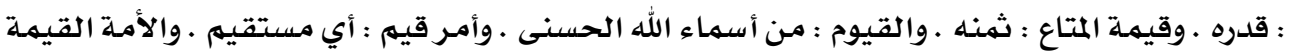

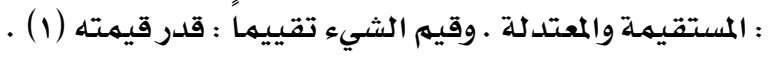

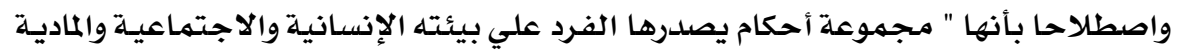

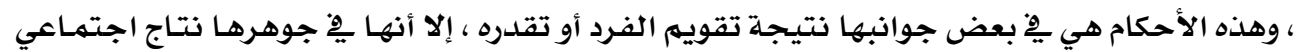

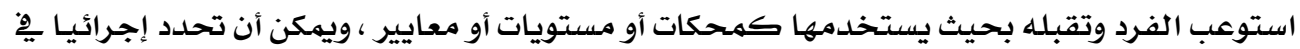

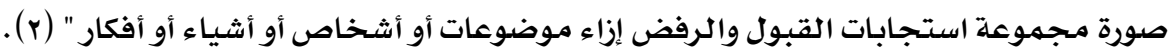

• القيم الدينية :

هي " القيم المنظمة لعلاقة الإنسان بالله تعالى وتحدد صلته بـه " (r) .

• القيم الجمالية :

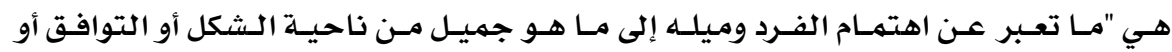

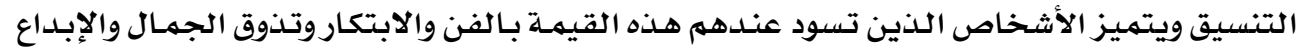

الفني ونتائجسه" (ع ) .

وتعرف الباحثة القيم الجمالية إجرائيا بأنها " تعبر عن الإحساس الداخلي للإِفراد عن مـا

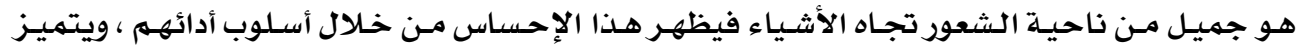

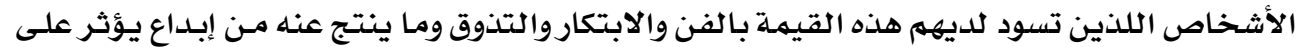

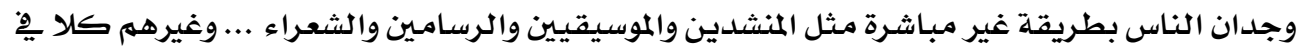

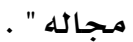

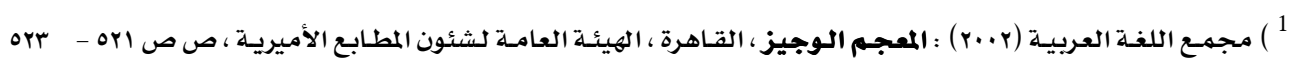
(بتصرف ). (1)

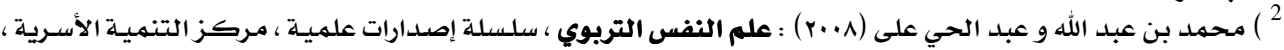

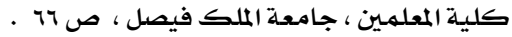

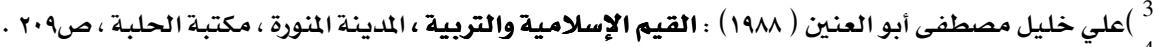

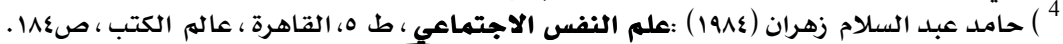


هِِ اللغة " ابتهل إلى الله : أي تضرع واجتهد ِِِ الدعاء " (1) .

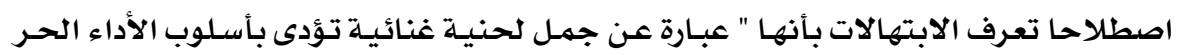

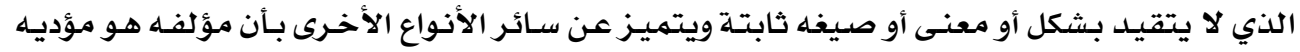

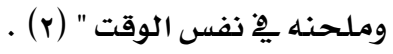

\section{الدراسات السابقة :}

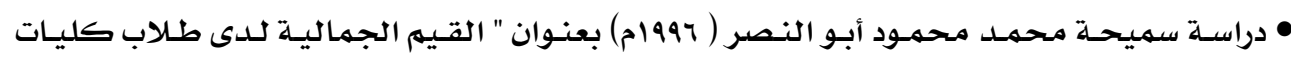

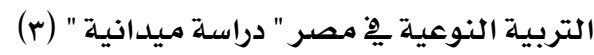

هدفت الدراسـة إلى تحديد وترتيب القيم الجمالية يِّ النسق القيمي لطلاب كليـات التربيـة

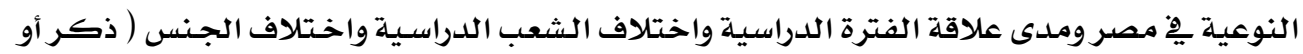

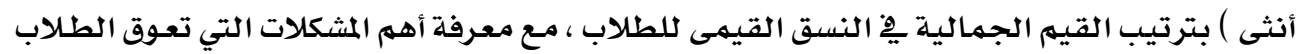

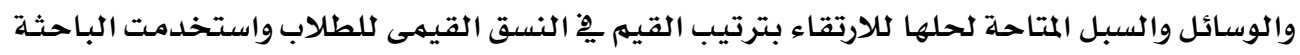

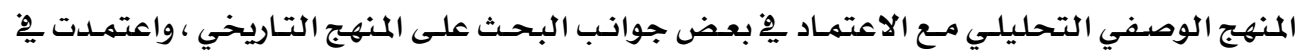

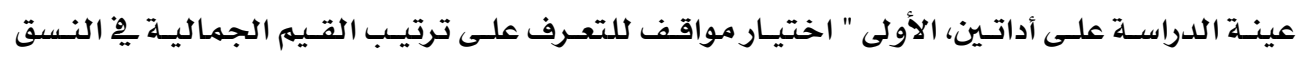

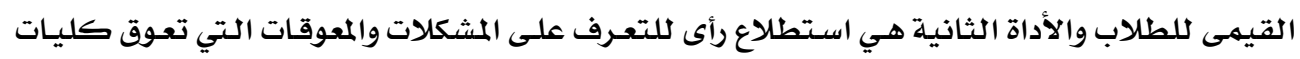

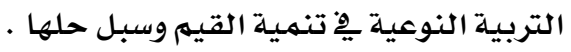

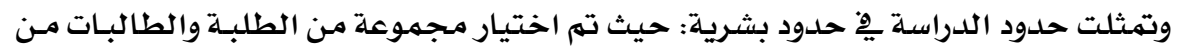

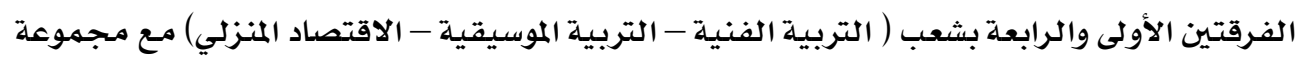

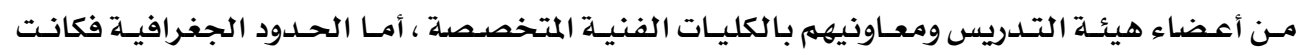

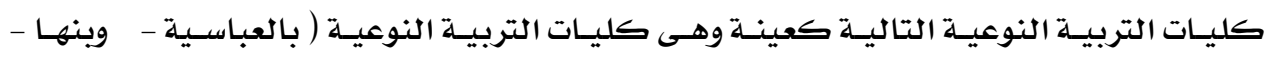

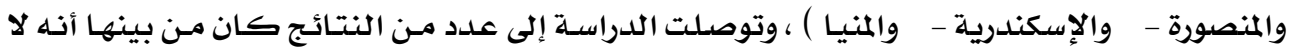

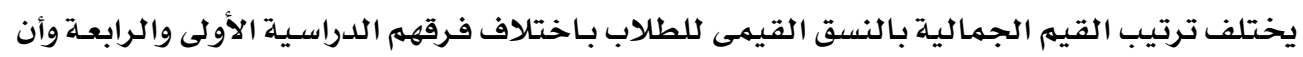

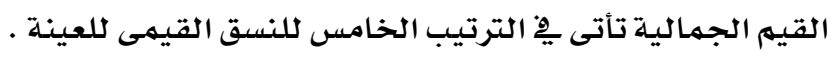

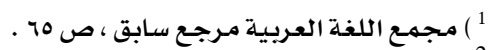

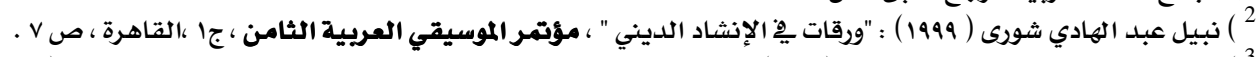

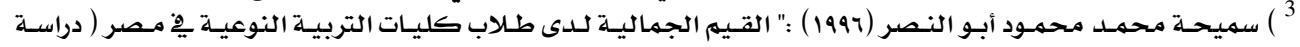

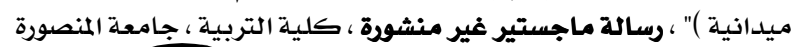




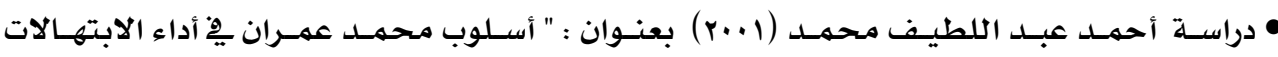

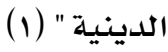

هدفت تلك الدراسة إلى تحديد الخصائص العامـة للابتهالات الدينية وتحديد أهـم أسـاليب

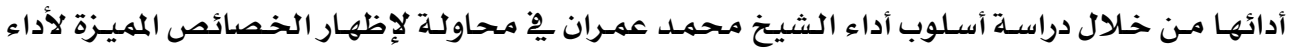

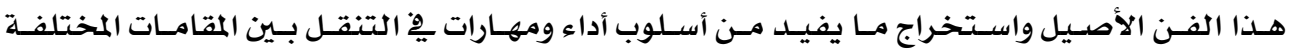

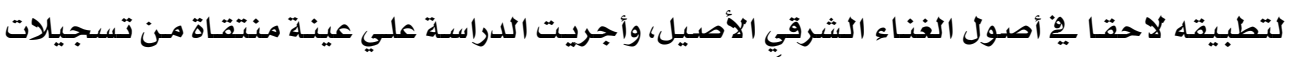

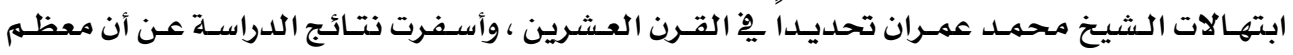

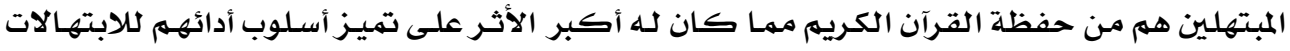

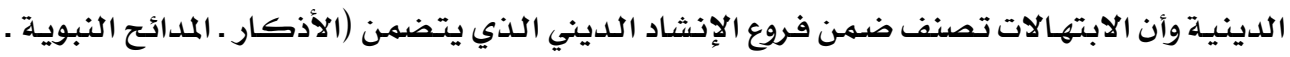

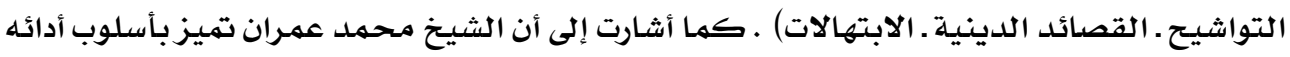

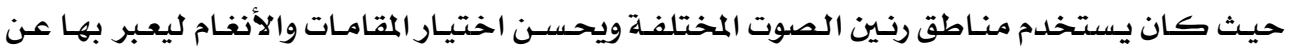

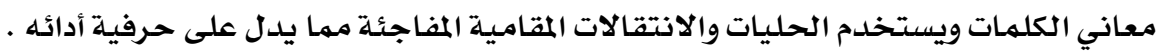

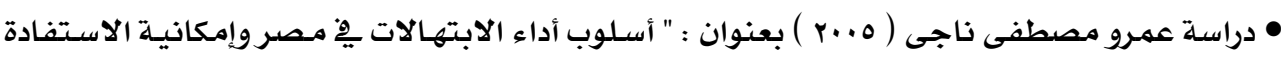

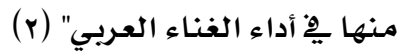

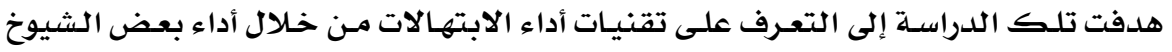

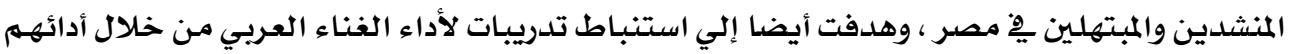

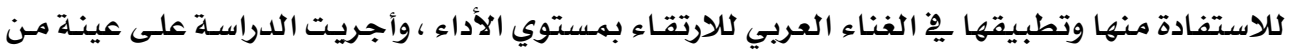

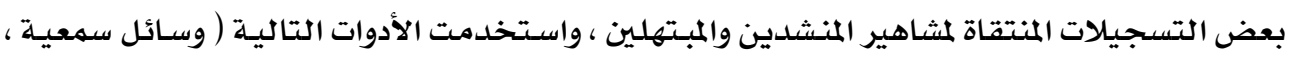

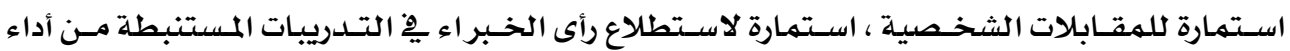

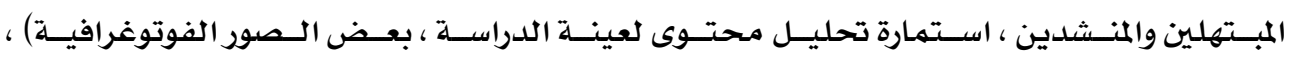

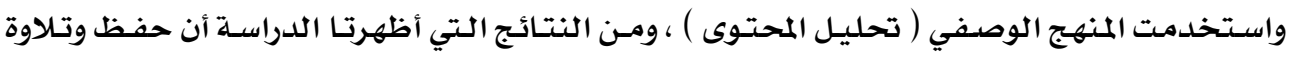

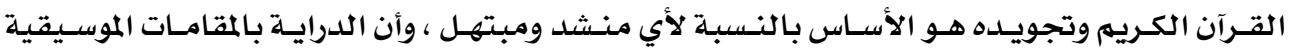

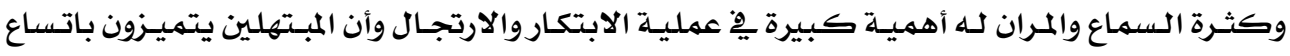

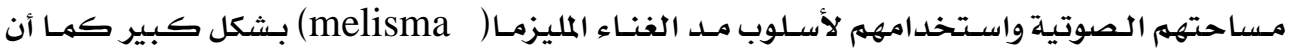

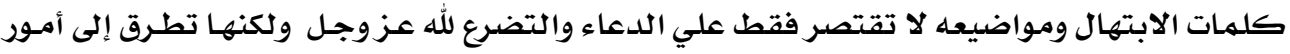
أخرى كثيرة تتعلق بالدين والدنيا . الابت ومواضئه

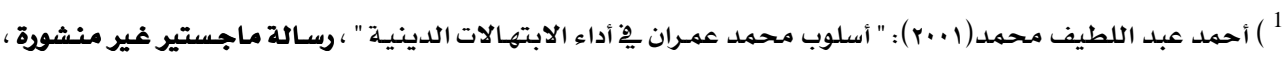

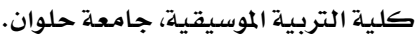

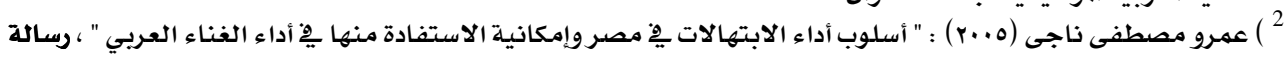

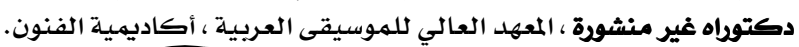




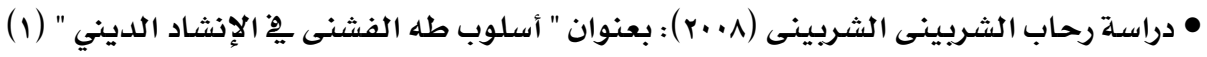

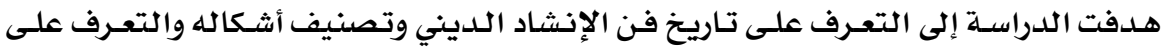

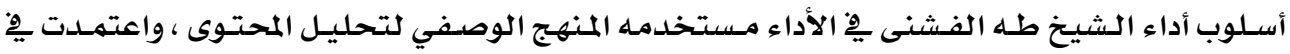

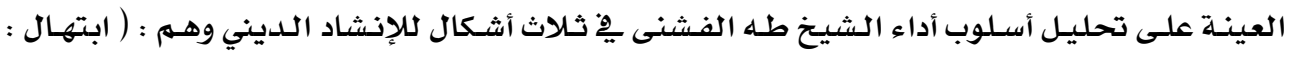

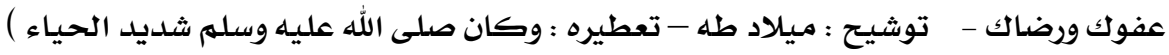

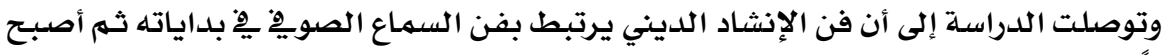

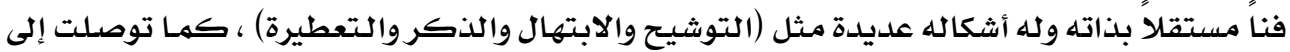

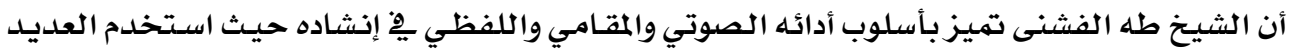

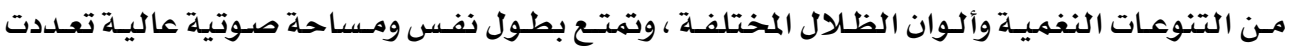

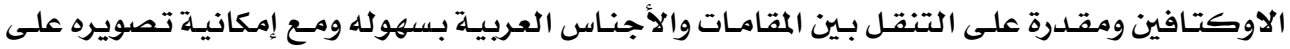

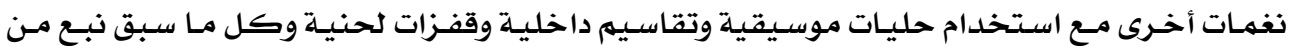

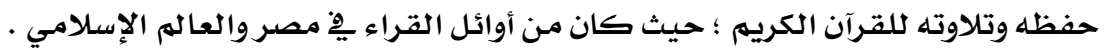

\section{التعليق العام على الدراسات السابقة :}

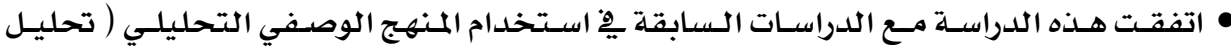

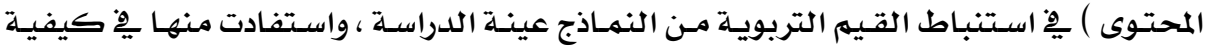

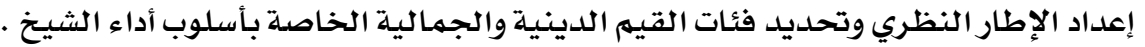
• واختلفت الدراسة مـع الدراسات السابقة ِِّ انه لا توجد دراسات تناولت القيم الدينية والجمالية

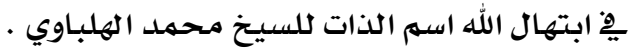
الإطار النظري للبـث البهار البه مقدمة :

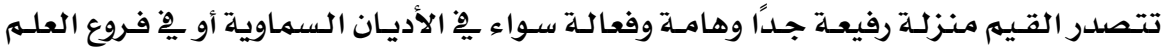

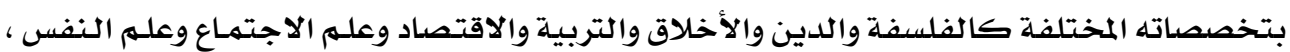

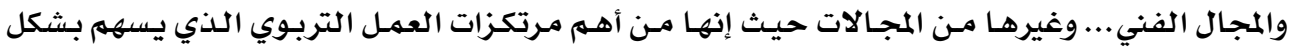

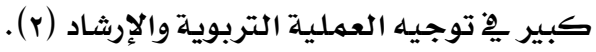
وحثي يتم التعرف علي القيم التربوية الإسلامية لا بلد مـن التعرف علي بعض مض مـن مجـالات

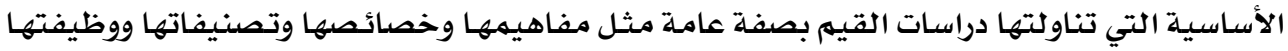

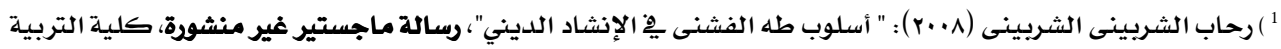
النوعية، جامعة طنطا. 2) اعبد اللطيف خليفة (.199 ) : ارتقاء القيم ، سلسلة عالم المعرفة ، العدد الاجل، المجلس الوطني للثقافة والفنون والأدب ،

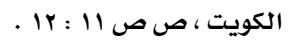


علي مستوي الفرد و المجتمـع لدراسة طبيعة القيه الإسلامية وتصنيفها ، والذي سيتهم ِِ ضوئده تفسير

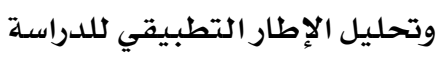

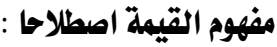

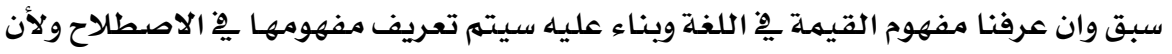

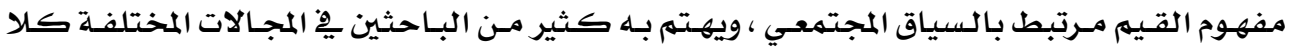

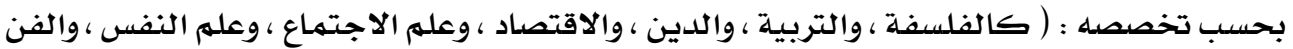

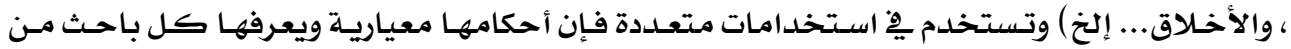

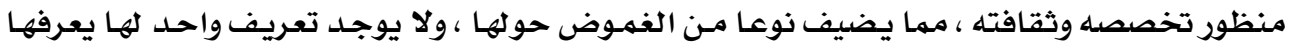

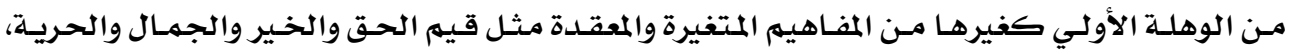

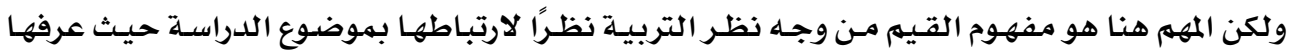

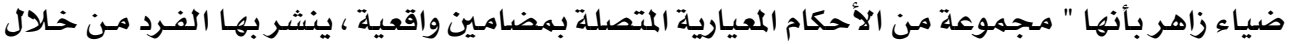

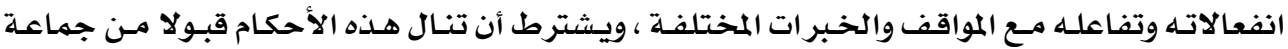

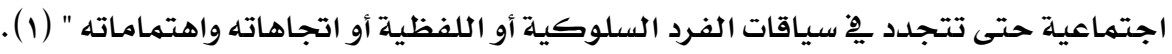

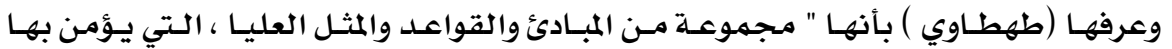

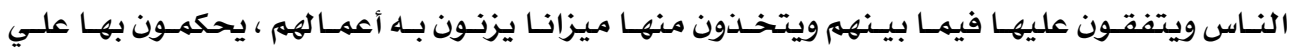

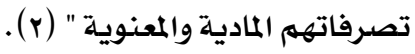

\section{تصنيف القيم :}

للقيهم تصنيفات عديـدة مختلفـة لأنها تـدخل ِِِ كثير مـن مجـالات الحيـاة ، ولا يوجــ لها

تصنيف جامع مانع ومنها :

تصنيف طهطاوى (r) : حيث صنف القيم الإسلامية إلى عدة مجالات، يمثل كل منها قيمـة

محددة وهى كالتالي :

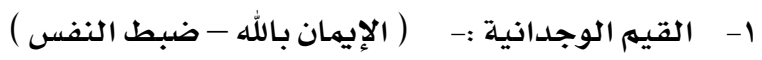

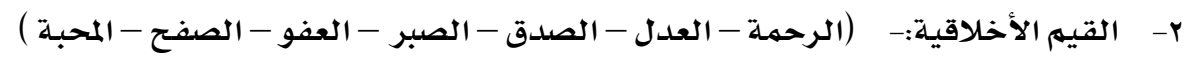

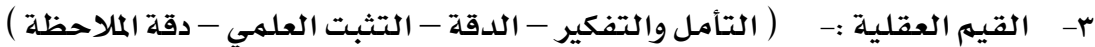

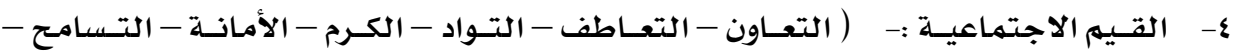

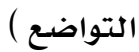

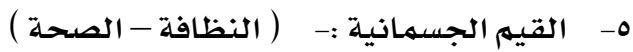

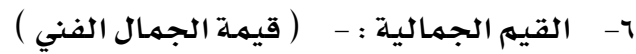

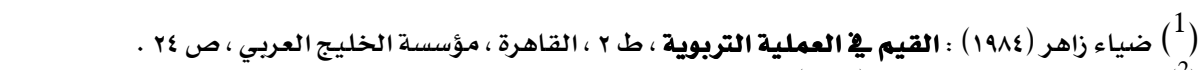

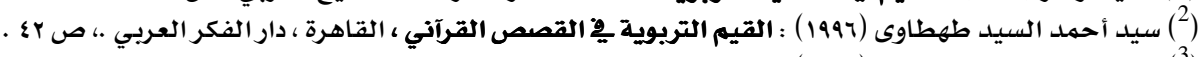

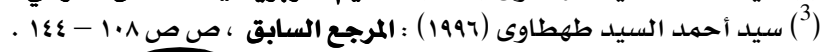




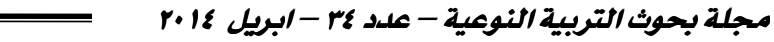

تصنيف الها شمى: اعتبر قيمة الإيمان هي القيمـة الأساسية التي تنطلق منها كل القيم،

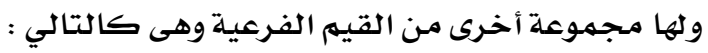
ا- البعـد الروحسي : ويشمل قيم (الـصلاة والتقوى والتوحيـد والخشية والرجـاء والحلهم والكـرم والأمانة والصدق)

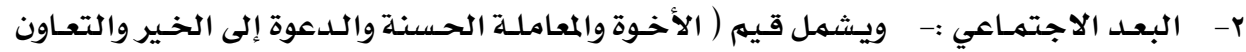

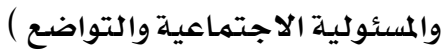

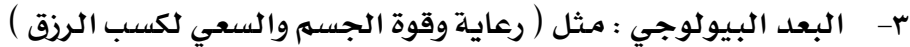

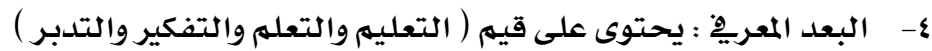

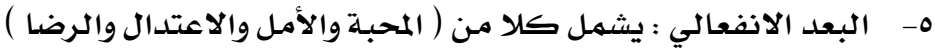

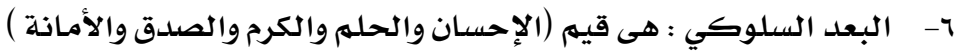
تصنيف ( البيهقي ) (1) : صنف القيم إلى أريع مجموعات كهما يلي : الابتهالات الدينية (r):

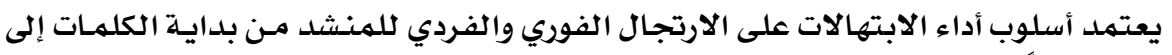

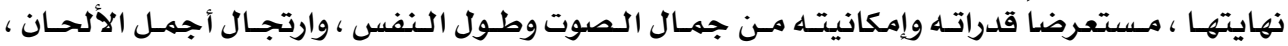

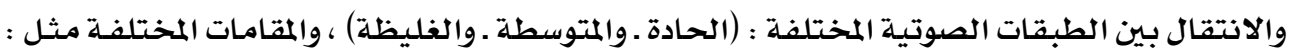

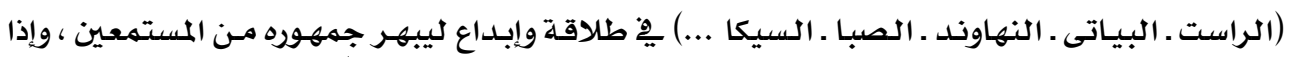

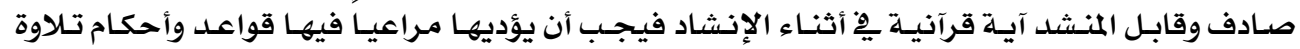

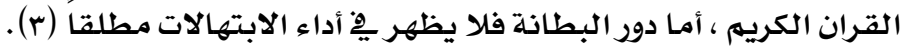

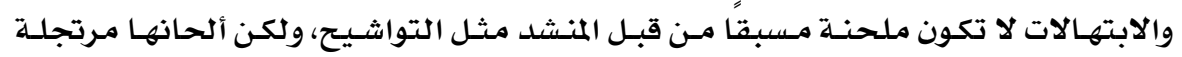

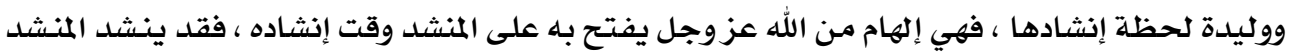

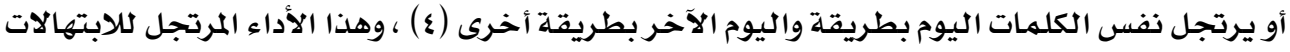

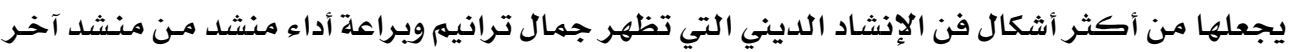

أحمـد بـن الحسينى بـن على البيهيقى (1999) : سـنـن البيهقى الكبرى ، تحقيق : مصطفى عبــ القـادر القط ، مكـة

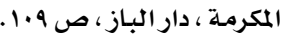

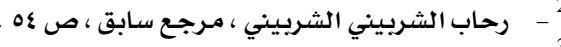

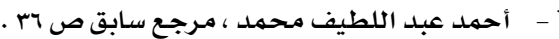

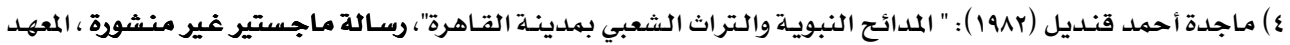

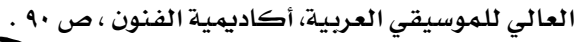




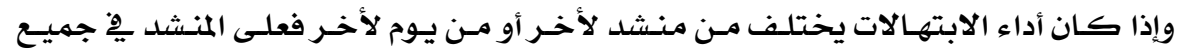

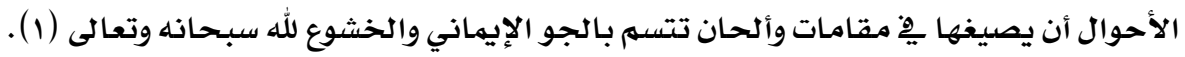

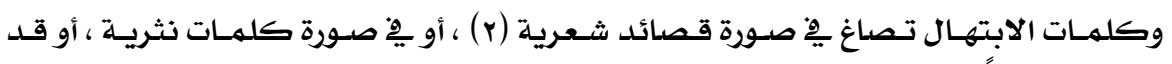

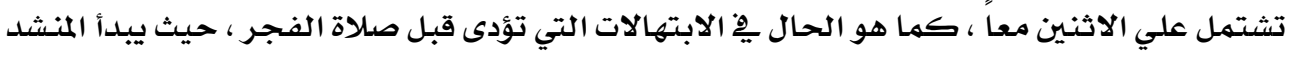

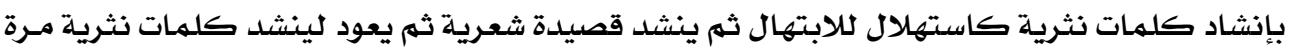

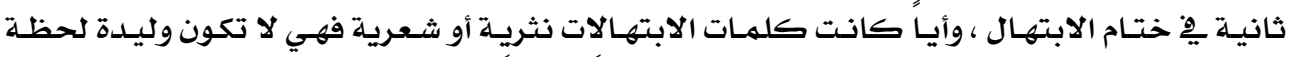

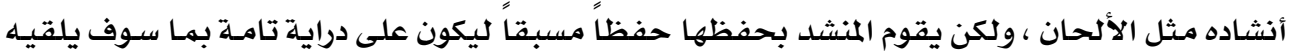

ومضمون نص كلمهات الابتهال يتنـاول أي موضـوع مـن الموضـوعات الدينيـة مثل: (دعاء لله

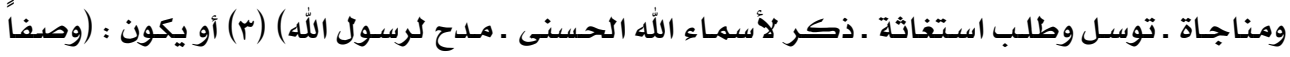

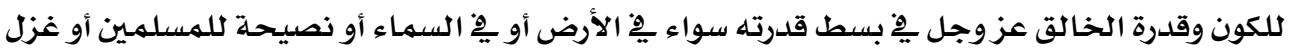

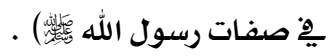

\section{السيرة الذاتية للشيخ محمد عبد الهادي محمد الهلباوي(ع):}

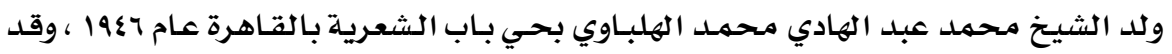

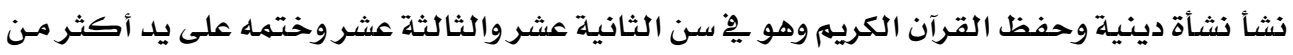

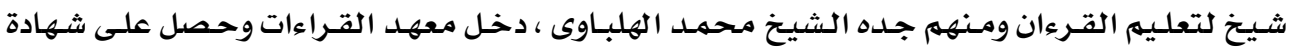

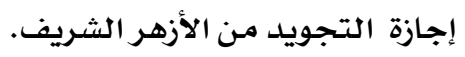

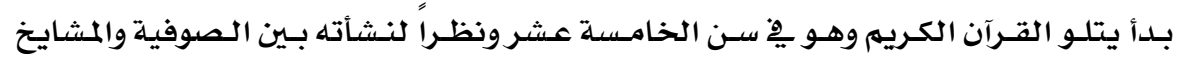

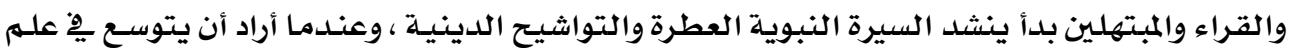

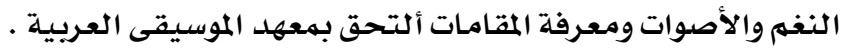
وحينما كان صغير السن كان يقتطع من مصروفة ليشترى الاسطوانات ويستمحع إليها

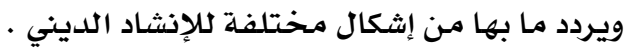

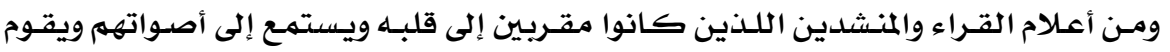

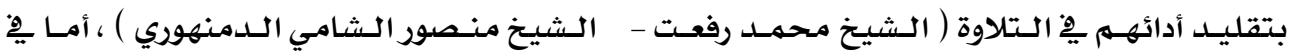

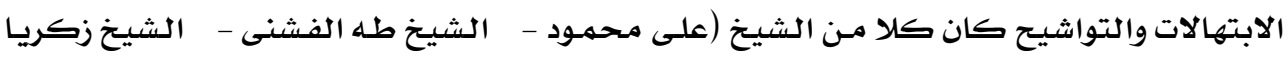

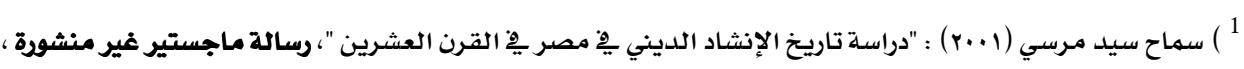

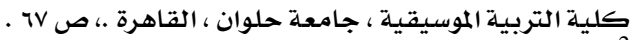

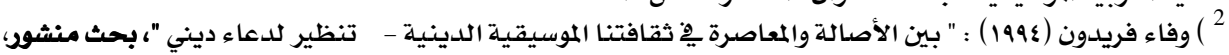

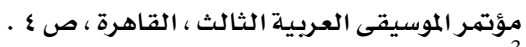

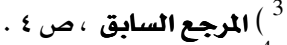
( 


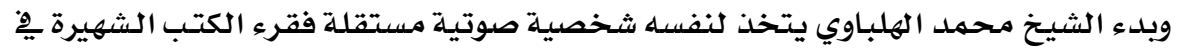

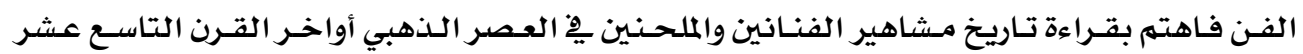

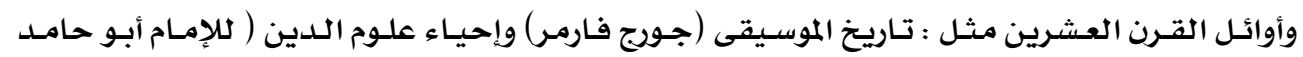

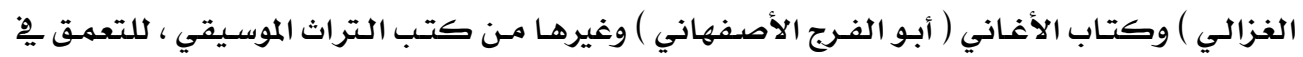

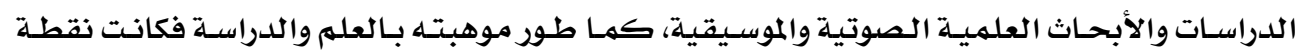

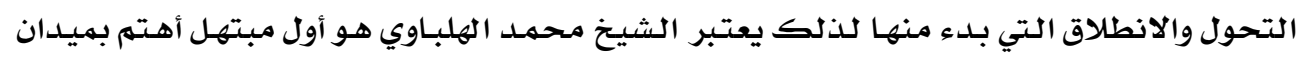

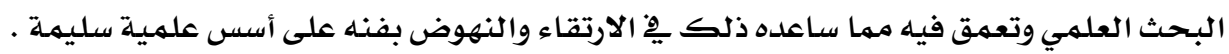

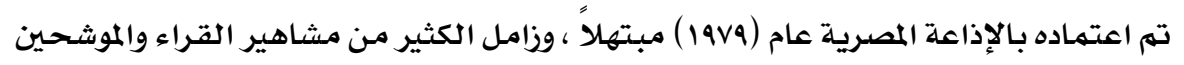

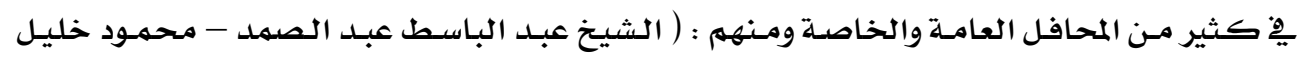

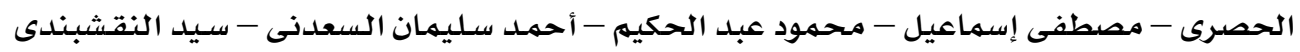

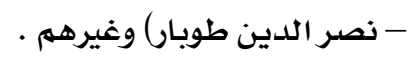

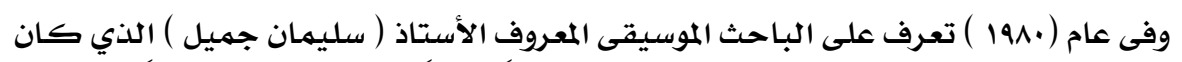

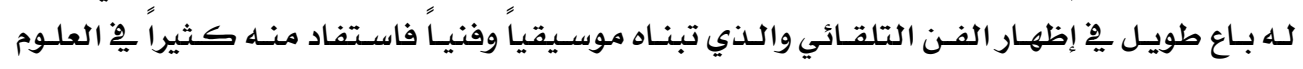
الموسيقية. أراد الشيخ محمد الهلبـاوى أن يتوج أعمالـه ويحـافظ على تراث فن الإنشاد الديني وأصوله

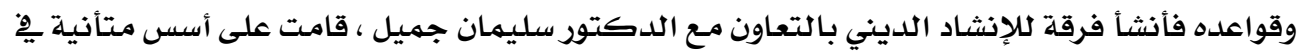

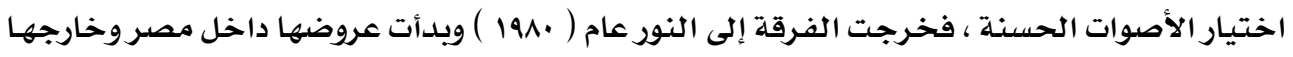

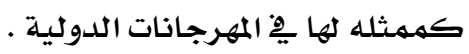

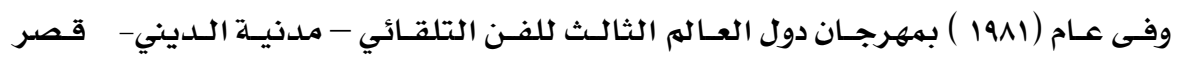

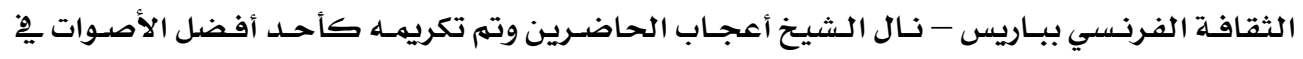

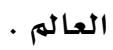

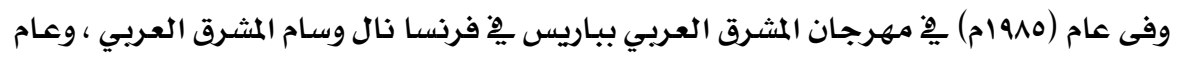

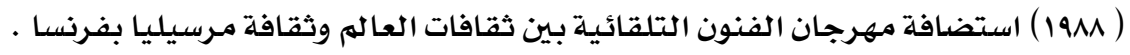

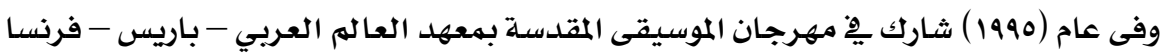

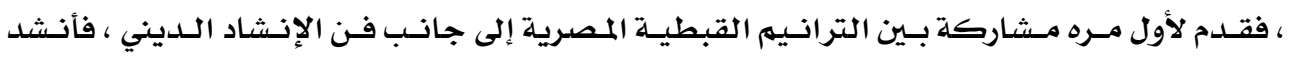
الابتهالات بمصاحبة السيمفونية رقم •ـ لموتسارت. وفى عـام ( 1991) تم استـضافته هِّ مهرجـان موسـيقى مـوزاربـأوبرا مرسـيليا وألقى فيهـا

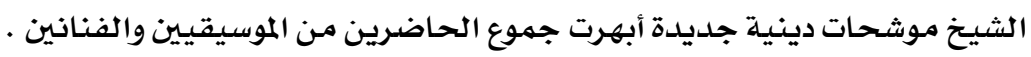

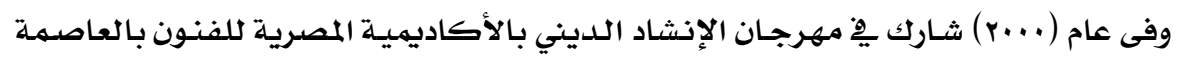

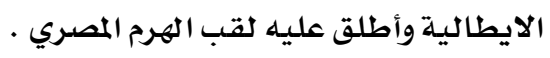




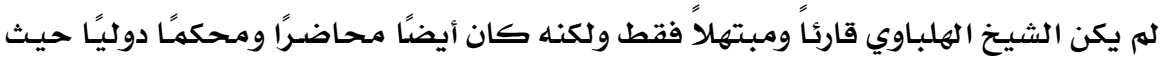

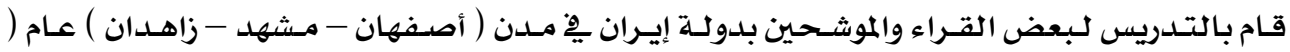

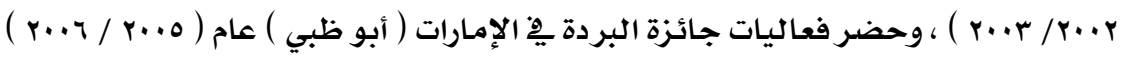

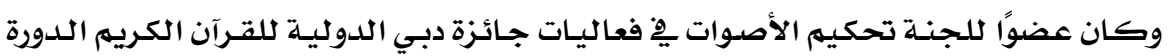

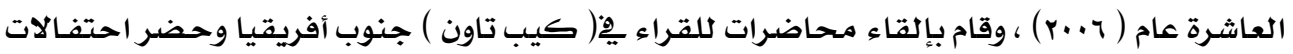

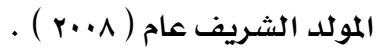

وشارك يِّ لجنة تحكيم المسابقة الدولية للقرآن الكريم ( بإيران ) عبر الفضائيات ( رمضان

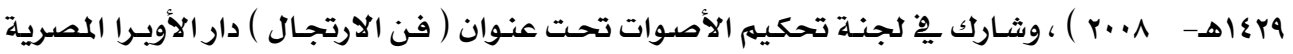
$\cdot(r \cdots \Lambda-11)$

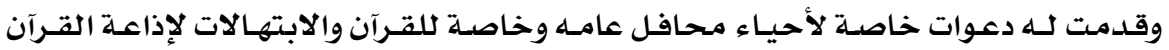

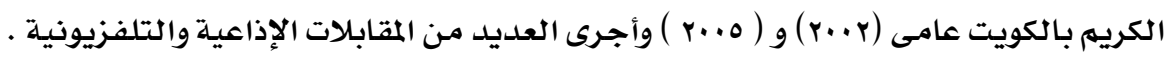

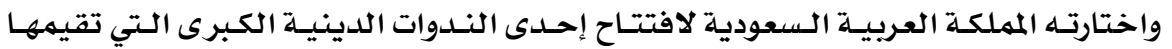

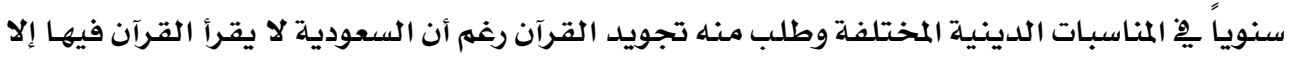
مرتلا.

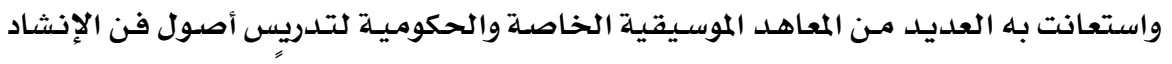

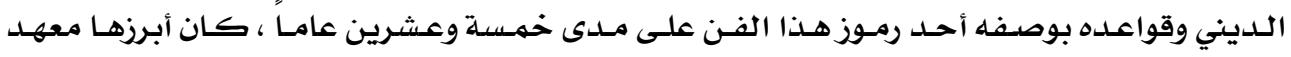

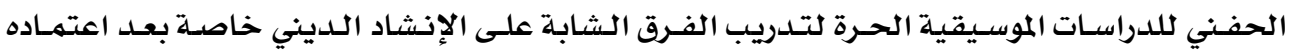
بوزارة الثقافة.

واعتبرت الإذاعة المصرية الشيخ محمد الهلباوي المبتهل الذي عوضها عن جيل الرواد خاصـة

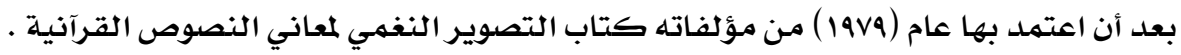

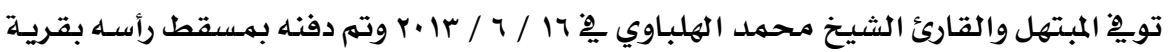

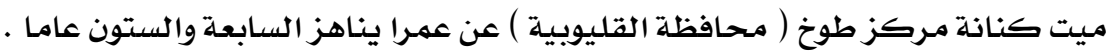


قائمة لبعض من ابتهالات الشيخ محمد الهلباوي

\begin{tabular}{|c|c|c|c|}
\hline 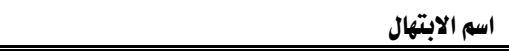 & 今 & اسم الابتهال & $\therefore$ \\
\hline طلع النهار على القمر & $r$ & إلهي قوي بالإيمان قلبي & 1 \\
\hline يا رب أدعوك في سري وأعلاني & $\varepsilon$ & اللّه اسم الذات & $r$ \\
\hline أشاد ربي به في صورة ألقلمي & 1 & جمالك في عيني وذكرك في فمي & $\circ$ \\
\hline بذكر الله تنشرح القلوب & $\wedge$ & قم فقد طاب سماعي & $r$ \\
\hline سبحان من قسم الأرزاق ولم ينس احد & 1. & إلهي يا من إذا سأله عبداً أعطى & 9 \\
\hline هل ترى عيني معائم طيبة فقيها من قلبي وقصدي وبغيتي & ir & يا رب ما لي في الوجود سواك & 11 \\
\hline ناح الحمام & $\varepsilon$ & يا مالك الملك يا من حبه ديني & ir \\
\hline ل لي في نوالكك يا مولاي أمال & 19 & كرامة المرى عند اللّ تقواه & 10 \\
\hline يا سيد الأنبياء واللدليل يا من به زال عنا الهم والنصب & in & إلى رحاب القدس سرت مكرما & iv \\
\hline يا عيد أهلاً & r. & يا رب بالمصطفى بلغ مقاصدنا & 19 \\
\hline وجهت وجهي إلى الرحمن في طلبي & rr & ألجأت ظهري إلى مولاي يحميني . & r \\
\hline أعمل حساب النفس عن شهواتها & rq & أهل الأمانة & rr \\
\hline يا هجرة المصطفى & rq & ما مثل قول الله عنه ثناء & ro \\
\hline جود بلطفك يا إلهي & ra & آمل ترقبه الزمان طويلاً . & rv \\
\hline رسول اللّه في ذكراك قربي & r. & أنت الذي لولاك ما سعت الصبا & ra \\
\hline ما بين ظل ونور & rr & شرف الزمان بليلة الإسراء & r \\
\hline أنا الفقير & 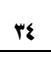 & تقيل نقسي إلى التقوى وترعاها & $r$ \\
\hline فاضت بالعبرة عيناه & rq & الكوز سبح للإله وكبر & ro \\
\hline
\end{tabular}

من خلال تتبع السيرة الذاتية للشيخ محمد الهلباوي والاستماع إلى الكثير من إعماله ، ترى

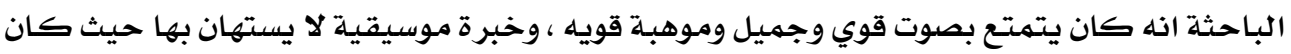

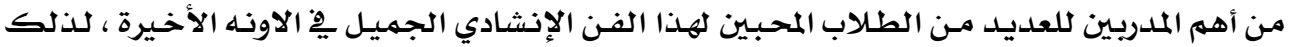

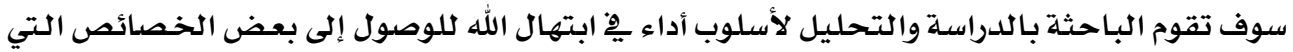

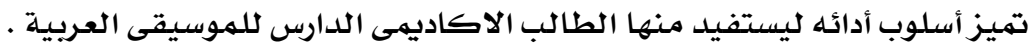


ابتهال : اللّه أسه الذات

أداء : المبتهل الشيخ محمد الهلباوي .

وهو الذي ندعوه بالرحمن

هو الصمد القوي مصور الإنساني

نورا يـراهُ القلب والعينان

ولن يحاط بكونه النوران

كون يا لا الجلال إذا ألتق الحرفان

عالماً بـل جـاهلً والجهل قد أغواني

لولاك ماكي يخ الخشوع يدان

إلى أن ينتهي لحقيقة الأعيان

متعبـدً بتلاوة القرآني
الله اسهم الذات جل جلاكله

سبـححان واحد أحداً

نور على نور وليس كمثله

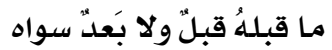

جل الذي إن شـاء أمـراً قال

$$
\text { يا رب إني مـا عصيتتك }
$$

وبهشرق الأنوار جئتحك خاشعاً

فأكشف غطاء الجهل عن بصري

وأختمم بخاتهـة الرضنا لموحلً

سبحـانك سبـحانك يا الله

\section{ابتهال/ الله}

ادائ المبتصل : محعد الهلباوي
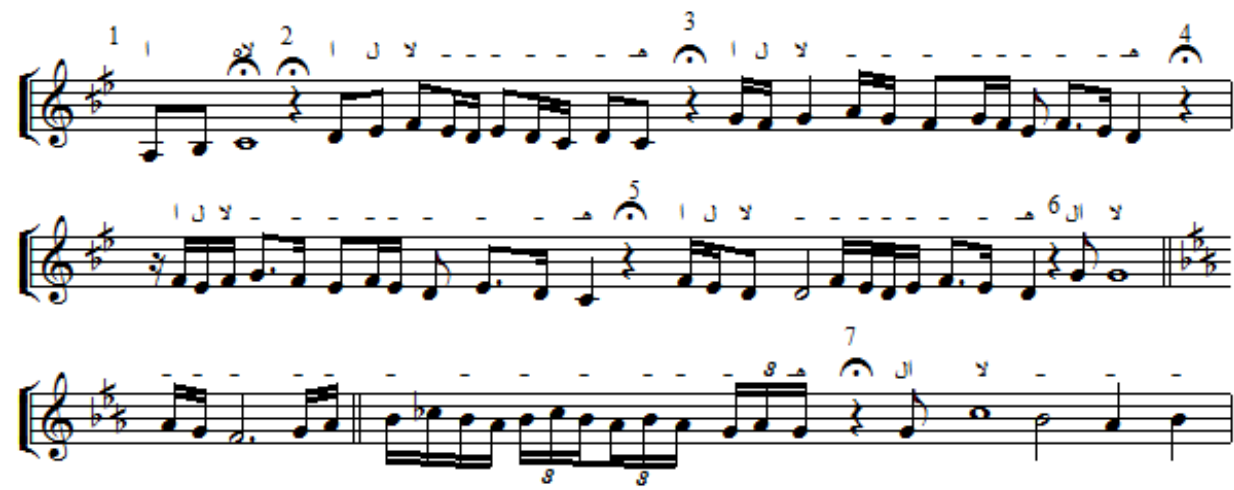


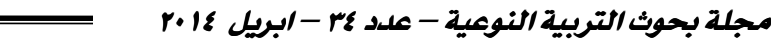

(ए)

(إ)

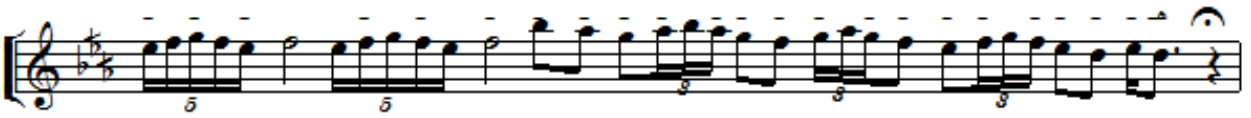

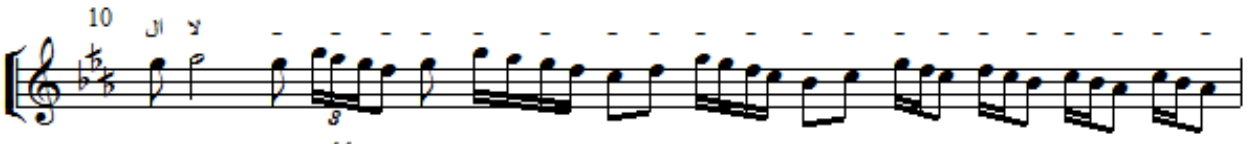
1112

(仵)

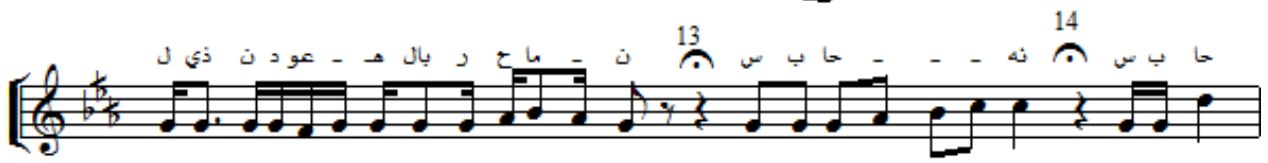

( 
(2)

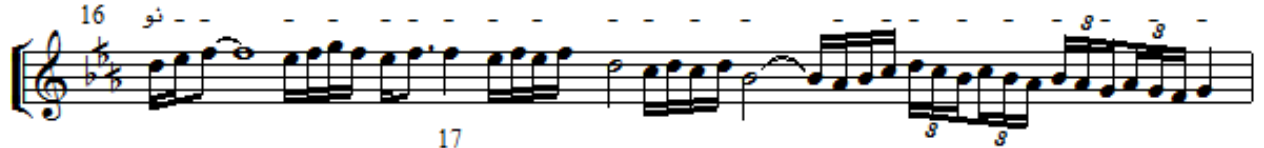

(1)

(18)

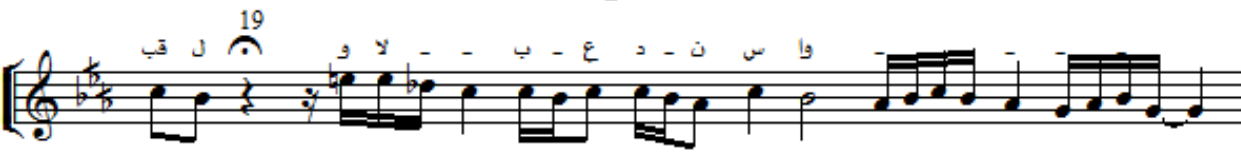

(إ)

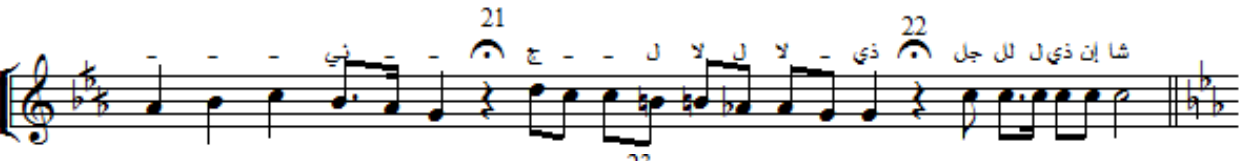
23

(2)

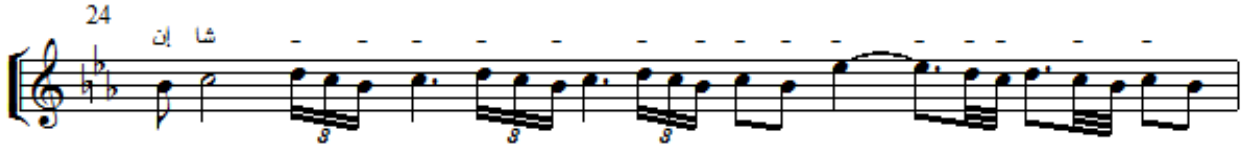

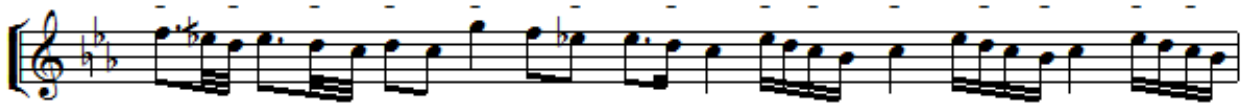

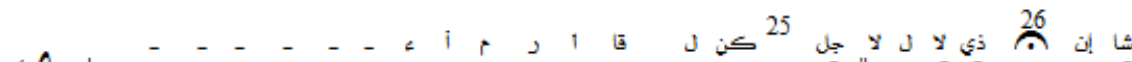

(6) 
مجلة بحوث التربية النوعية - عدد غr - /بريل ع.1\&

(6)

27

(6)

(2)

(2)

(1)

31

(1)

(2)

(E)

(2)

(5)

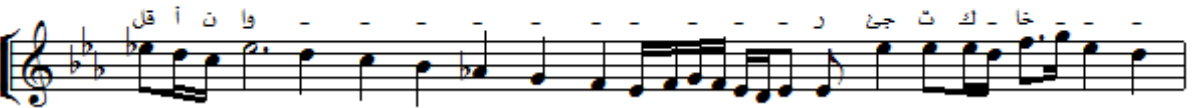




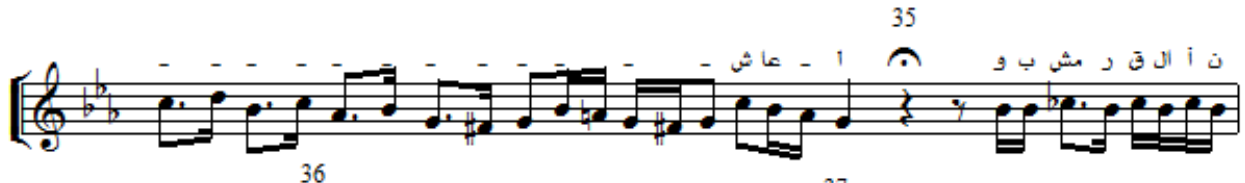
(2)

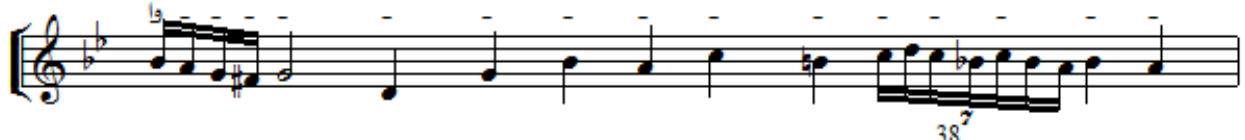
$\left(\frac{b}{6}\right.$ (E) ( (1)

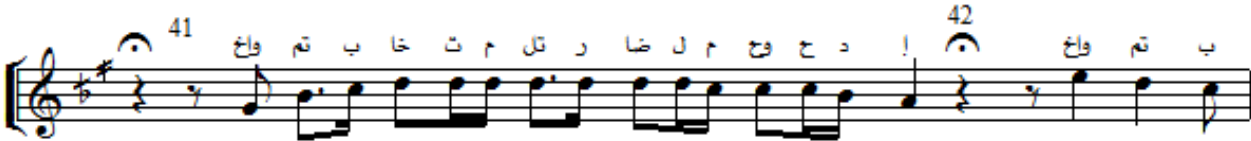

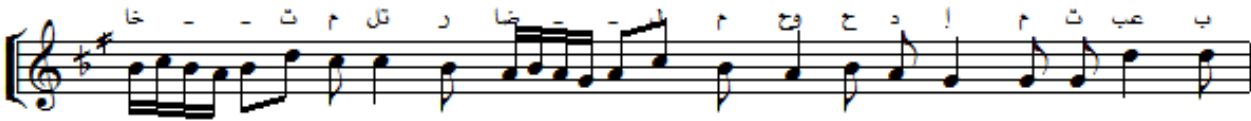

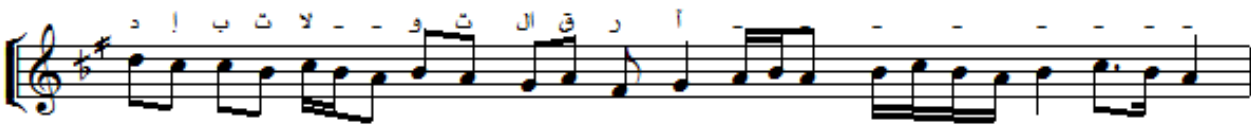
43

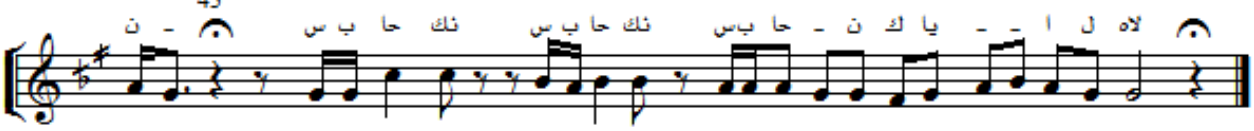




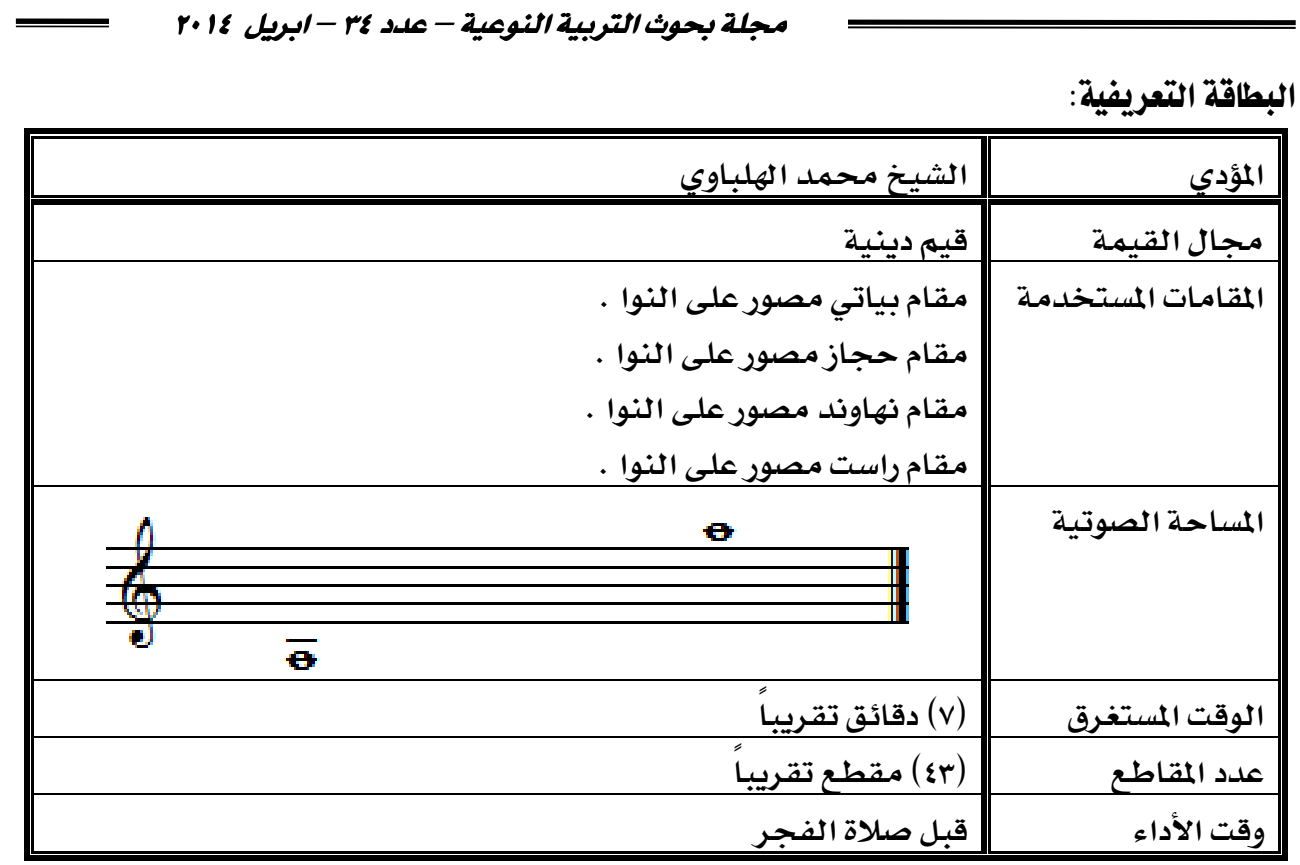

تحليل القيم الدينية بالنموذج الأول ابتهال (الله أسم الذات) :

$$
\begin{aligned}
& \text { ا- من المقطع رقم (1) إلى المقطع رقم (ع) : } \\
& \text { وهو الذي ندعوه بالرحمن } \\
& \text { الله أسهم الذات جل جلالكه } \\
& \text { الصمد القوي مصور الإنساني }
\end{aligned}
$$

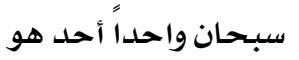

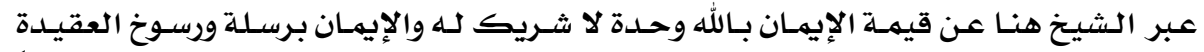

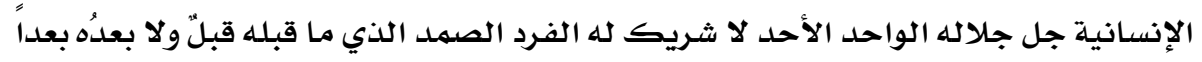

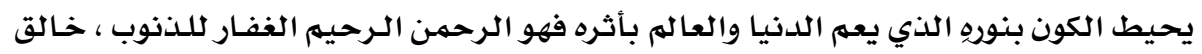

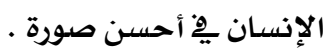

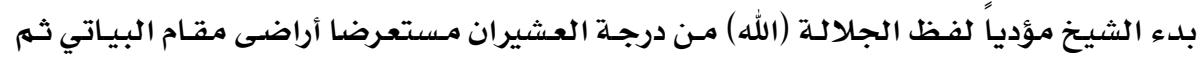

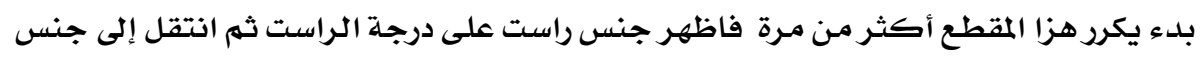

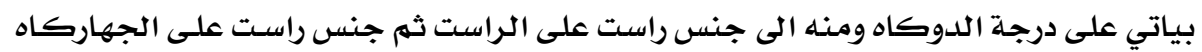

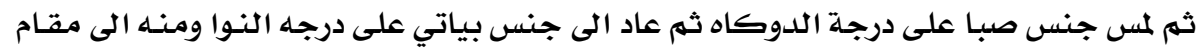

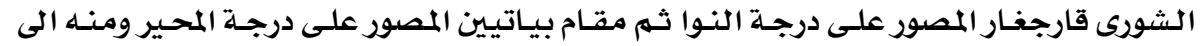

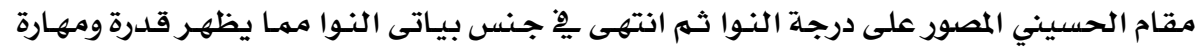

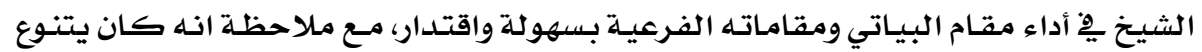

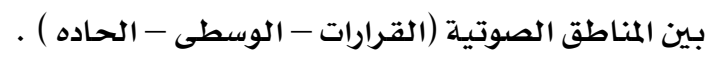




\section{$\theta+3$}

(

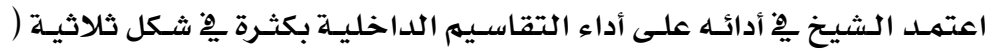

وشكل خماسيه (

5

يلاحظ مرونتة يِ التنقل بين أماكن الرنين الصوتية مـع إيجاده يِّ توزيع النفس بحسب طول او قصر الجملة بحسب طول الجملة اللحنية .

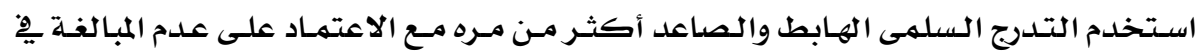

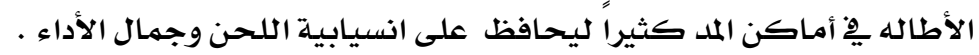
يلاحظ استخدام أسلوب المليزما بكثرة على حروف المد ( الألف والواو والياء ) .

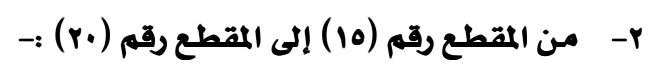

$$
\begin{aligned}
& \text { نور على نوروليس كمثلـه نوراً يراه القلب والعينان } \\
& \text { ما قبله قبل ولا بعده سواه ولهم يحاط بكونه النوران }
\end{aligned}
$$

تضمنت الكلهـات قيمـة المداومـة على ذكـر الله ليل نهار بالتسبيح والدعاء فبـذكر الله تنشـر

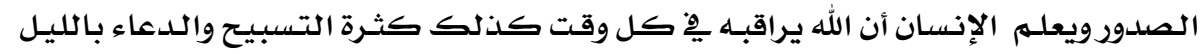

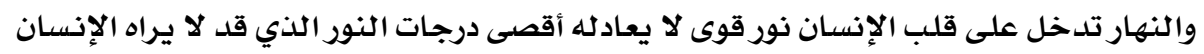

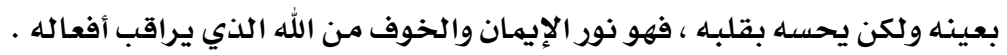

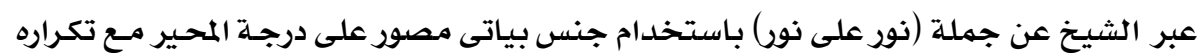

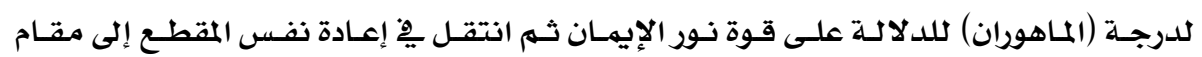

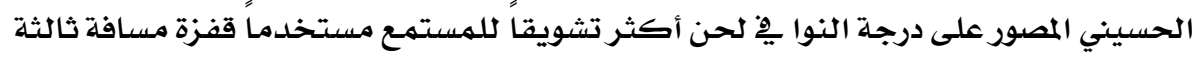
هابطة وأسلوب الثبوت النغمي على أكثر من درجة صوتيه منها (الماهوران - المحير - العجهم)

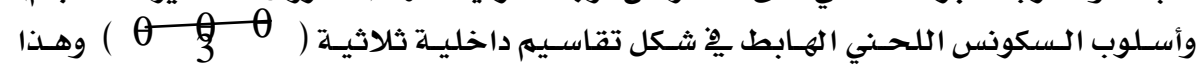

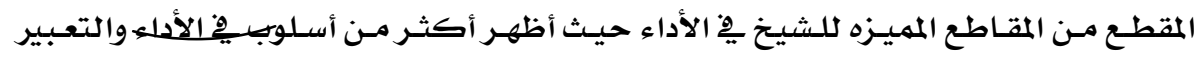

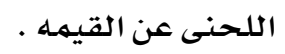

قام بأداء جمله (وليس كمثله شيء) يِّ جنس راست على درجة الكردان مـع ملاحظ أدائه قفزة

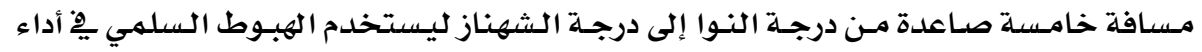

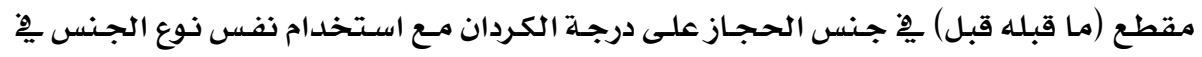

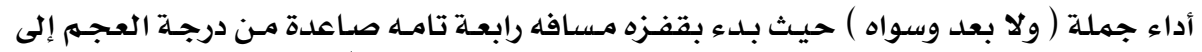

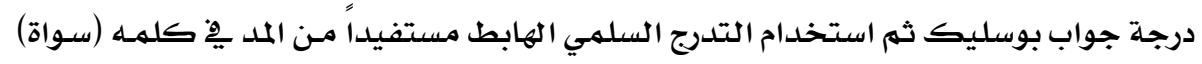

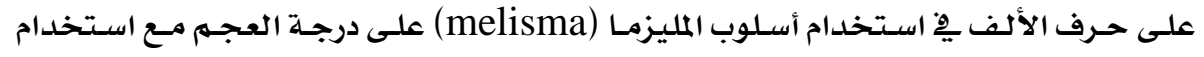

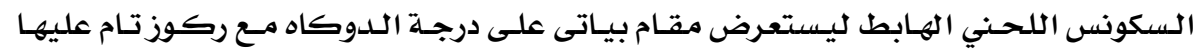

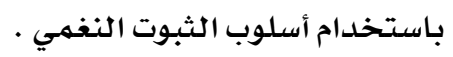




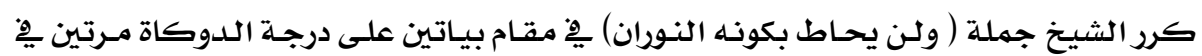

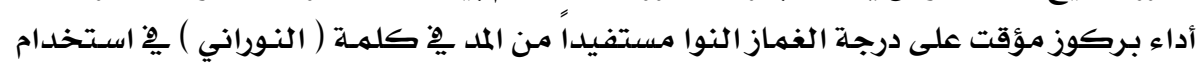

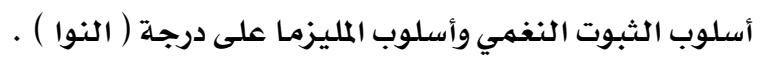

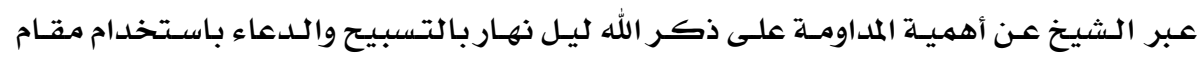

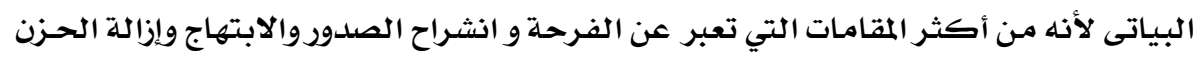

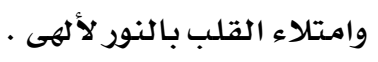

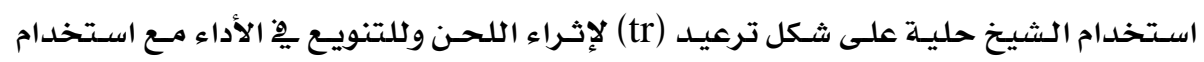

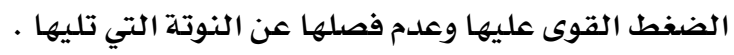
r- من المقطع رقم (r) إلى المقطع (rq) :-

جل الذي إن شاء أمراً قال كون يا لا الجلال إذا التقى الحرفان

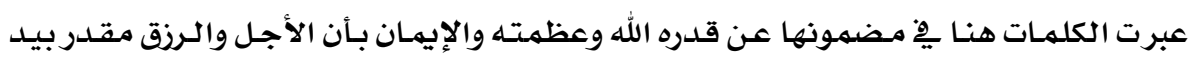

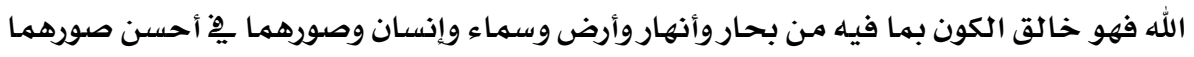

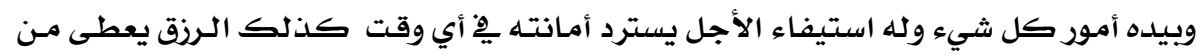

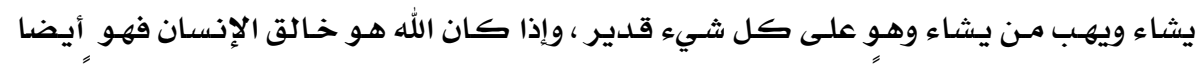

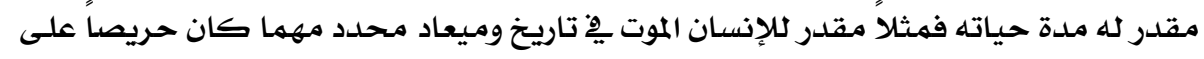
حياته .

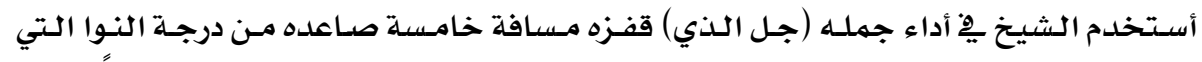

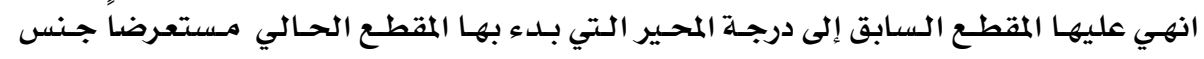

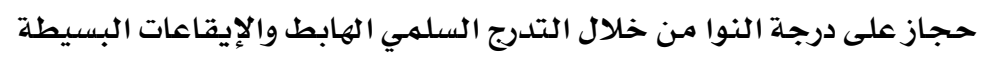

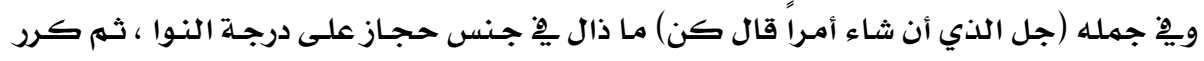

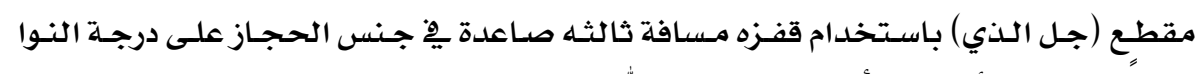

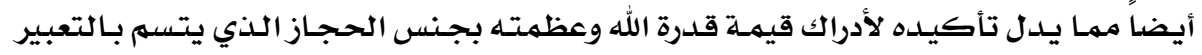

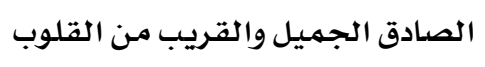

وٌِِ المقطع (إن شاء أمراً قال كن) أستعرض جنس نهاوند إند على درجة الكردان للتنويع وتشويق • المستهـع

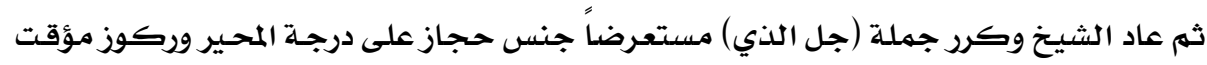

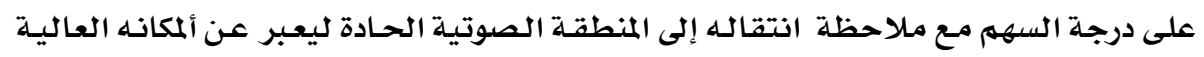

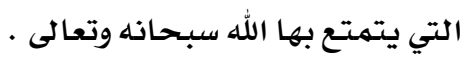

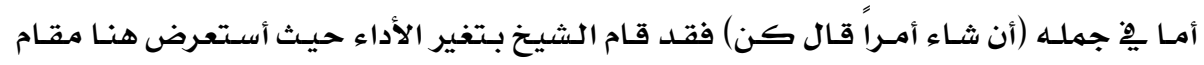

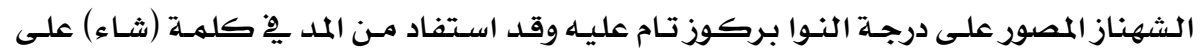

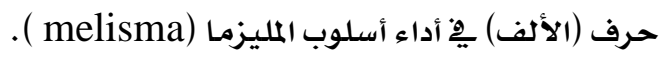




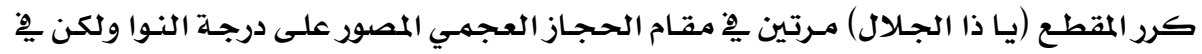

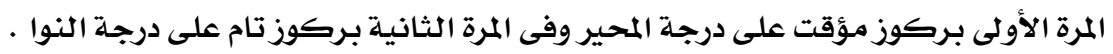

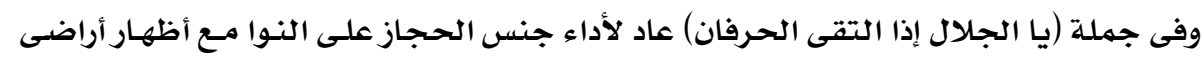

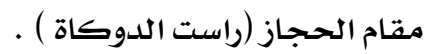

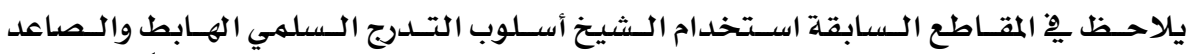

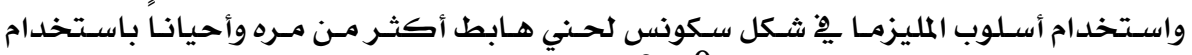
التقاسيه الداخلية يخ شكل ثلاثية (

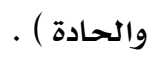

$$
\begin{aligned}
& \text { ع- من المقطع رقم (.r) إلى المقطع رقم (rr) : }
\end{aligned}
$$

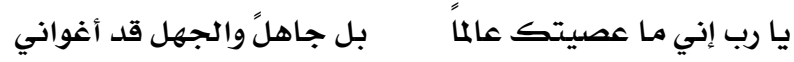

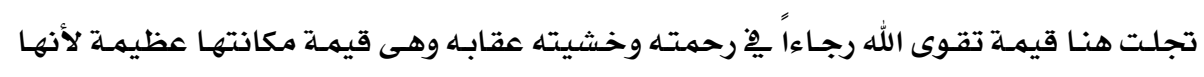

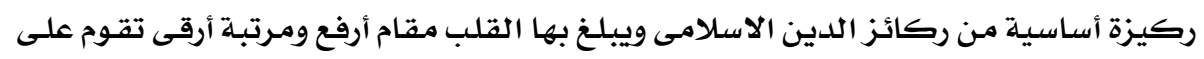

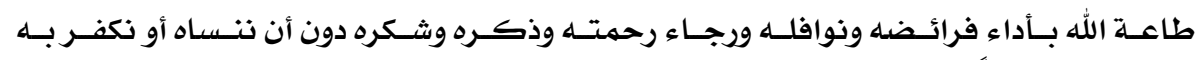

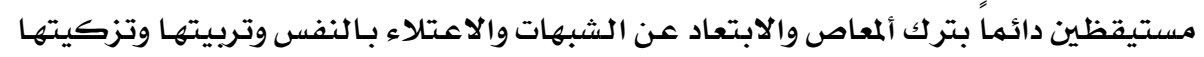

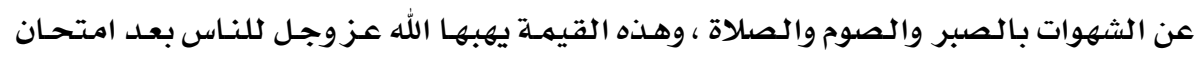

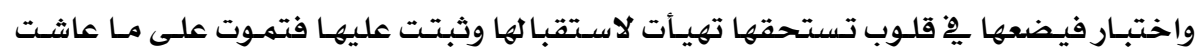

$$
\text { عليه من اليقين والتقوى . }
$$

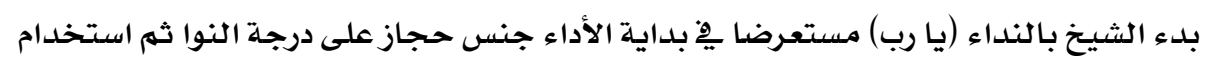

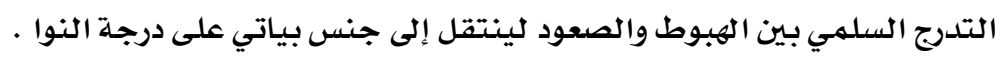

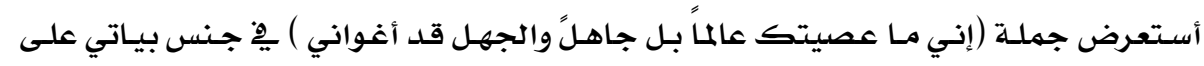

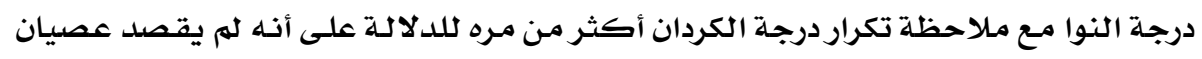

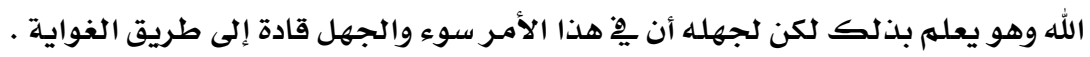

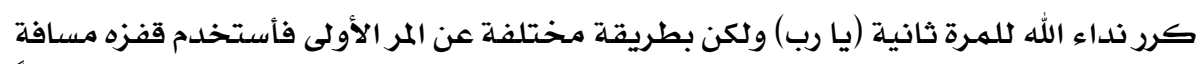

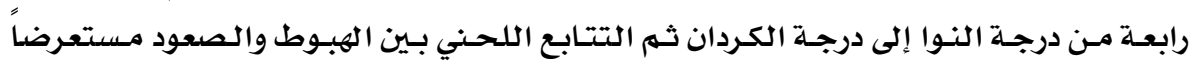

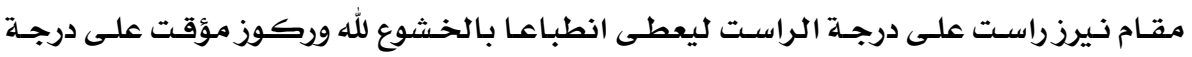

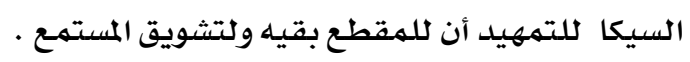

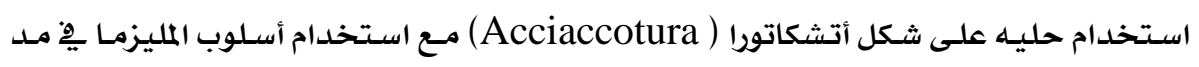

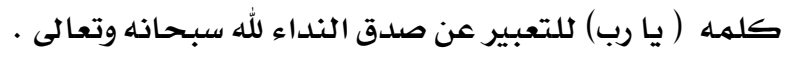

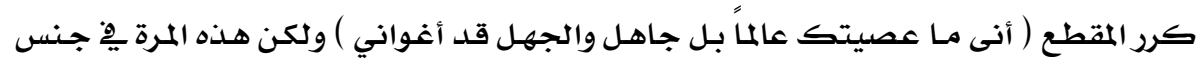

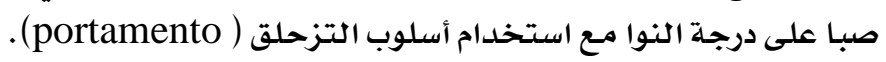


0- من المقطع رقم (ع) إلى المقطع رقم (rq) :

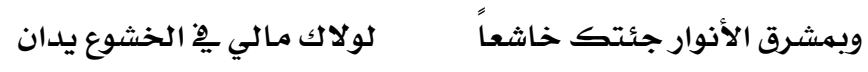

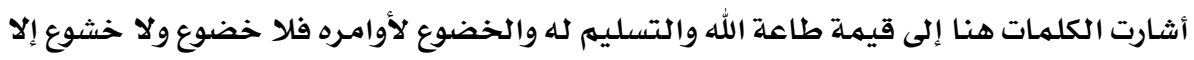

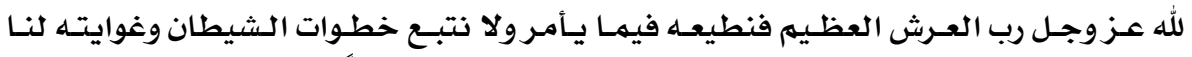

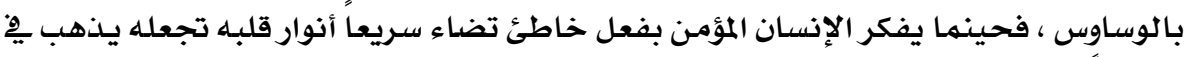

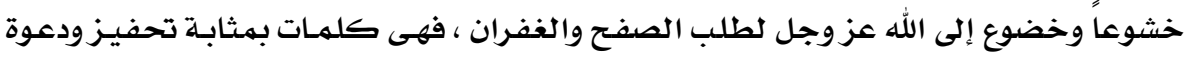

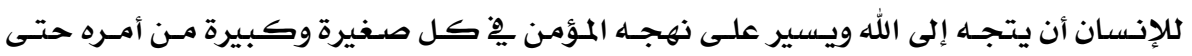

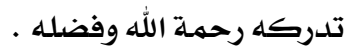

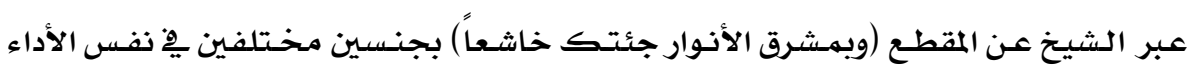

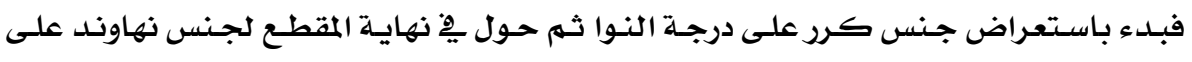

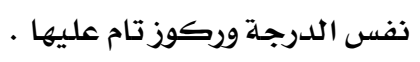

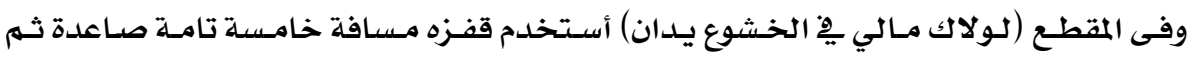

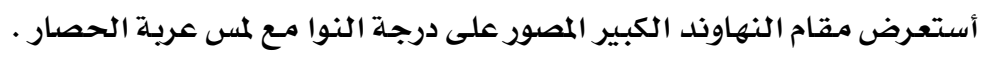

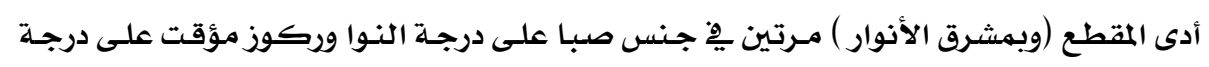

$$
\text { تيك نهفت . }
$$

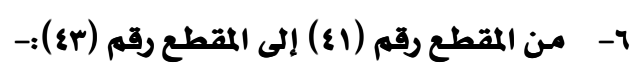

فأكشف غطاء الجهل عن بصري إلى أن ينتهي لحقيقة الاعيان

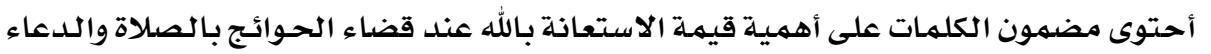

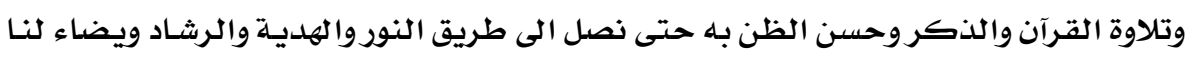

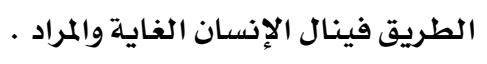

وفى المقطع (فأكشف غطلـاء الجهل عن بصري) أستعرض جـنس بيـاتى على درجـة الحسـين

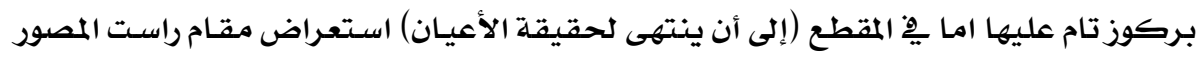

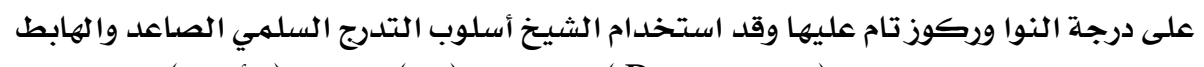

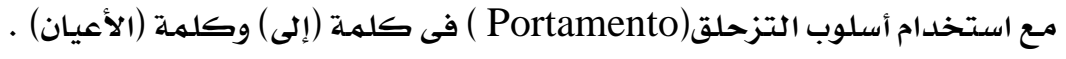

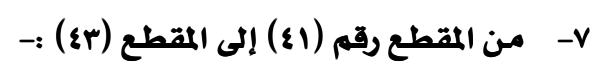

$$
\begin{aligned}
& \text { وأختم بخاتمة الرضا لموحدً متعبداً بتلاوة القرآني } \\
& \text { سبحانك سبحانك يا الله } \\
& \text { عبرت الكلمات عن قيمة تعظيم شعائر الله مثل }
\end{aligned}
$$

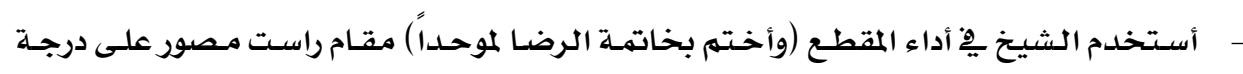

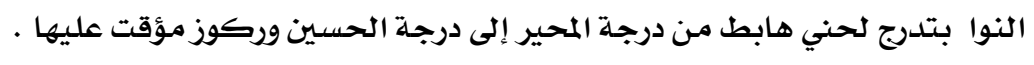


وفى المقطع (وأختم بخاتمـة الرضـا لموحد اً متعبداً بتلاوة القرآن) أسـتعرض مقـام راست المصور

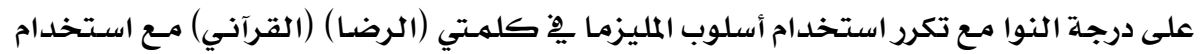

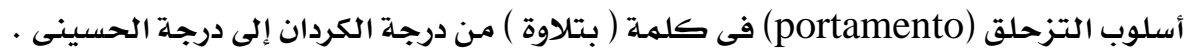

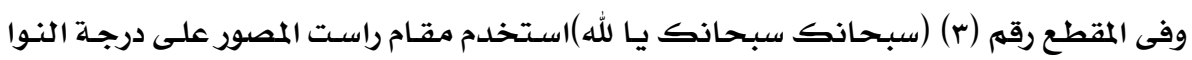

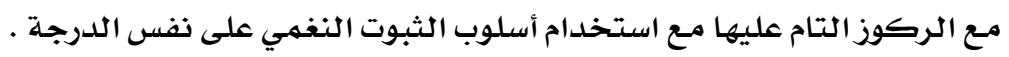

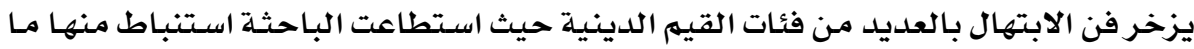

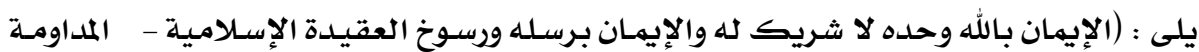

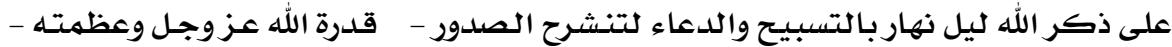

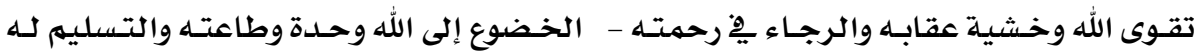

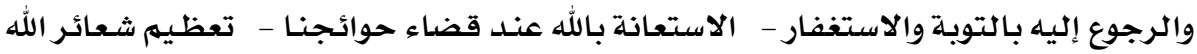

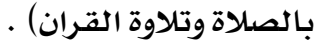
•تمكن الشيخ محمد الهلبـاوي مـن أداء الكثير مـن التنويعـات النغميـة وأسـاليب الأداء التعبيريـة

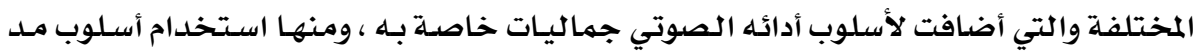

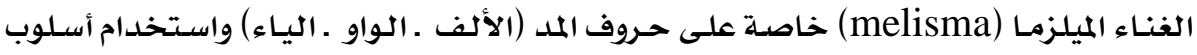

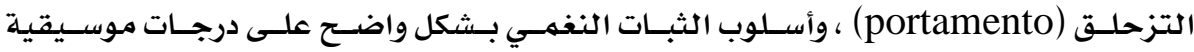
مختلفة .

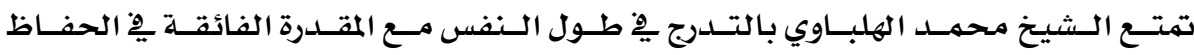

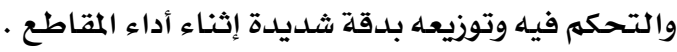

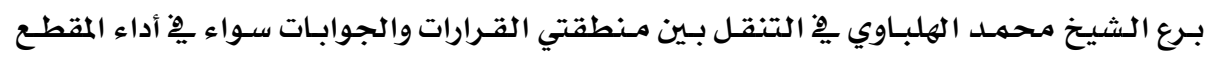

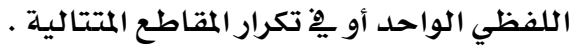

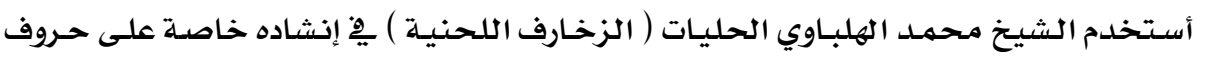

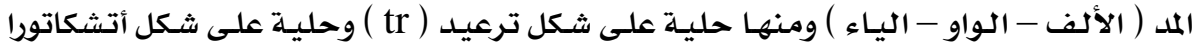

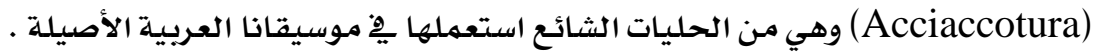

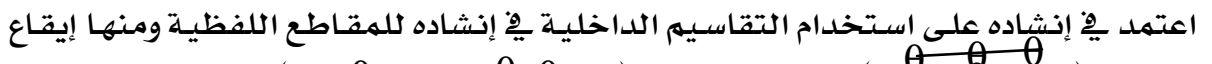
الثلاثية ( )

وفق الشيخ محمد الهلباوي يِّ اختيـار مقامـات وأجنـاس تـتلائم مـع طبيعـة الكلهـات التي يقوم

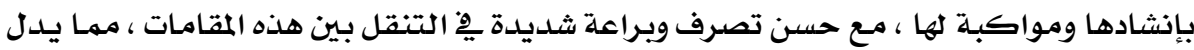

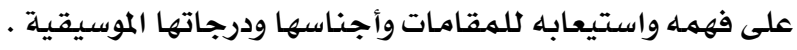




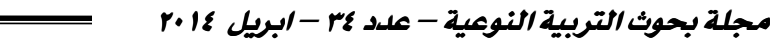

ه استخدم القفزات اللحنية المتنوعة مثل قفزة مسافة : ( ثالثة ـ رابعة ـ خامسـة ـ سادسـة ـ سـابعة .

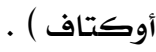

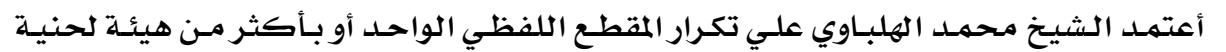

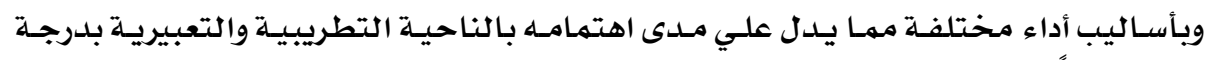

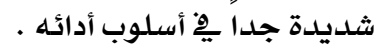

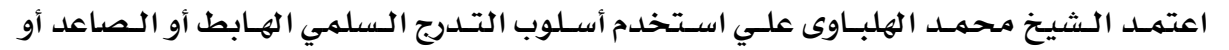

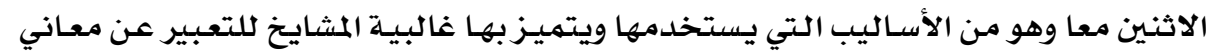

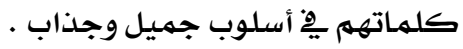

اختيـار بعـض التواشـيح والابتهـالات الدينيـة لتـدرس ضـمن مقـررات الموسـيقى العربيـة لأنها

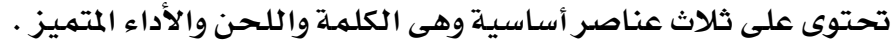

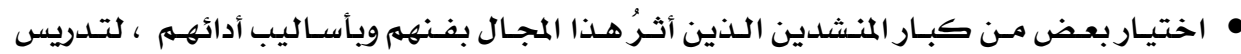

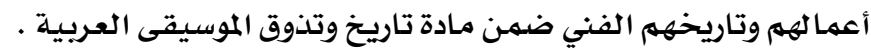

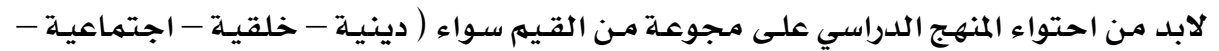
وطنية ..... ) حتى نصل للهدف الأكبر وهو التربية أولا ثم التعليهم .

ا. أحمد بن الحسينى ابن على البيهيقى (1999 ) : سنن البيهقى الكبرى، تحقيق: مصطفى عبد القـادر القط ،

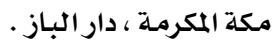

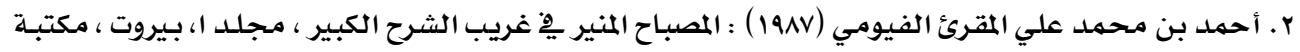
لبنان .

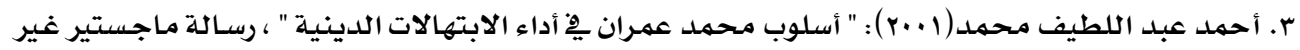

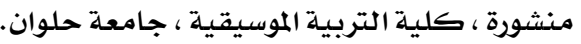

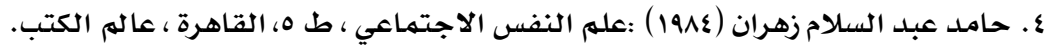

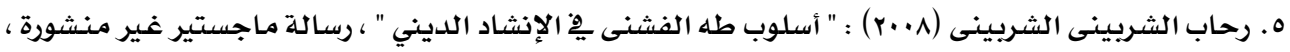
كلية التربية النوعية ، جامعة طنطا.

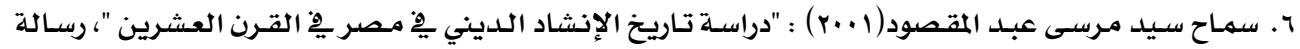

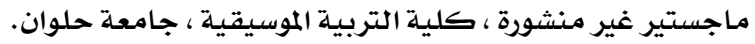

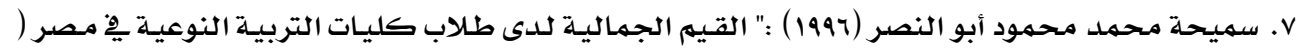

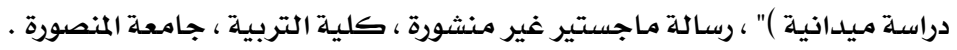

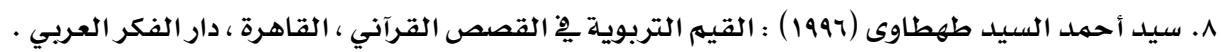

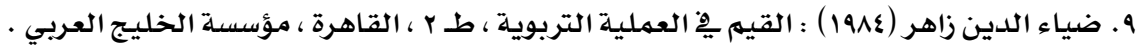




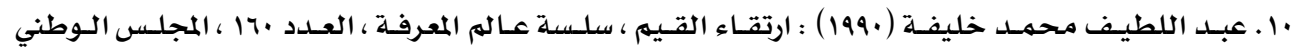
للثقافة والفنون والآداب ، الكويت.

ال . على خليل مصطفى أبو العنين (19MM ) : القيهم الإسلامية والتربية ، المدينة المنورة ، مكتبـة إبراهيم حلبي .

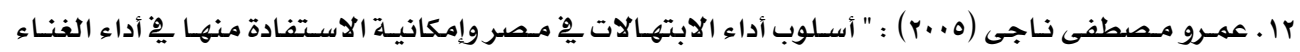
العربي " ، رسالة دكتوراه غير منشورة ، المعهد العالي للموسيقى العربية ، أكاديهية الفنون.

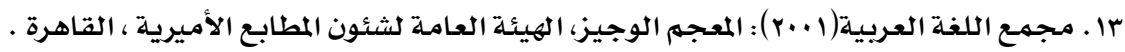
ع ا ـ محمد بن أبى بكر بن عبد القادر الرازى (71911) : مختار الصحاح ، مجلد ا 1 ، بيروت، مكتبـه لبنان .

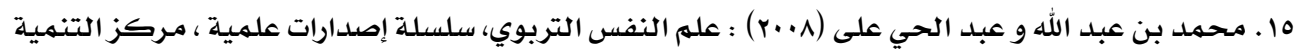
الأسريـة ، كلية المعلمـين ، جامعة الملك فيسك فيصل.

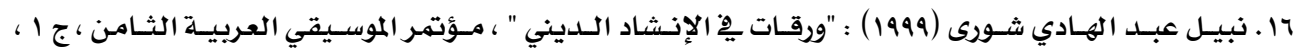
القاهرة.

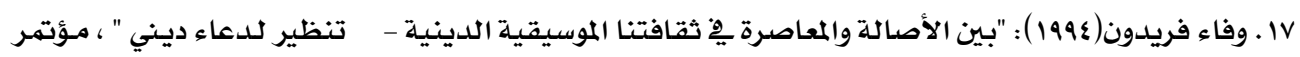
الموسيقى العربية الثالث ، القاهرة . 


\section{Abstract}

Dealt researcher in this research study religious values and aesthetic in prayer (God is the name of self) to Sheikh Mohammed Helbawi as a form of art, religious recitation, amounts of human behavior and values governing human relationships and on the basis of the social life and without them living community as individuals without prompt or as a state without a constitution, so appeared several studies on different types of values and categories depending on the type of specialization and area to which it belongs, and that the art of singing religious in its various forms includes Semitic message from which to re- organize the content of the various decisions of the Arab music insert models choir simple makes it easier for student study and take advantage of them .

\section{The theoretical framework:}

it addressed the researcher the following elements:

- The concept of values idiomatically

- Classification of values: where it has many different categories as they enter in many areas of life, and Has no rating Collector, including (Thtauy rating - Bayhaqi rating).

- The concept of religious invocation and performance style

- Biography of Sheikh Mohammed Helbawi

- A list of some of the prayers, Sheikh Mohammed Helbawi.

\section{Applied frame:}

it addressed the researcher the following elements:

- Identify the invocation (God is the name of self) to Hlbawi.

- Analysis and the development of the most important religious values and aesthetic style performance-Sheikh .

\section{Search results:}

Abounding art invocation of religious numerous categories of religious values as managed researcher devised, including the following: (faith in God alone with no partner and faith in His Messengers and stability of the Islamic faith - Continuously mention God day and night with praise 
and supplication to Tnscherh breasts - the power of God Almighty and greatness - piety and fear punishment and hope in his mercy - to submit to God's unity and obey him and his delivery and return him to repent and seek forgiveness - the use of God when you spend Hawwaijna - Maximize the rites of God in prayer and recitation of the Quran).

Sheikh Mohammed Helbawi able to perform many of the aesthetic values for the manner of performance, including :

- Variations tonalities and methods of performance expressive different and that added to the style of performance audio aesthetics of its own, including the use of $\mathrm{D}$ singing (melisma) special on $\mathrm{ABC}$ tide (thousand waw AZ) and the use of style skiing (portamento), and the method of constancy tonal clearly scores different musical

- Gradient along with the self-estimated high to maintain, control and distribution very precisely during the performance sections.

- Navigate between different areas, including audio (resolutions - and the answers), both in the performance of one syllable or syllables in successive repetition.

- The performance of ornaments (melodic motifs) in a private sing on $\mathrm{ABC}$ tide, including the ornament in the form of (tr) and Ornament in the form of (Acciaccatura), one of the ornaments commonly used by our music in authentic Arabic.

Then the researcher concluded Find a set of recommendations and a list of references and a summary of scientific research. 